\section{SANDIA REPORT}

SAND96-0984 - UC-814

Unlimited Release

Printed April 1996
$E: \cdots=$

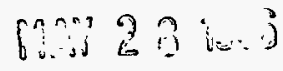

(a) 31

\title{
A Viscoplastic Theory for Braze Alloys
}

M. K. Neilsen, S. N. Burchett, C. M. Stone, J. J. Stephens

\section{Prepared by}

Sandia National Laboratories

Albuquerque, New Mexico 87185 and Livermore, California 94550

for the United States Department of Energy

under Contract DE-AC04-94AL85000

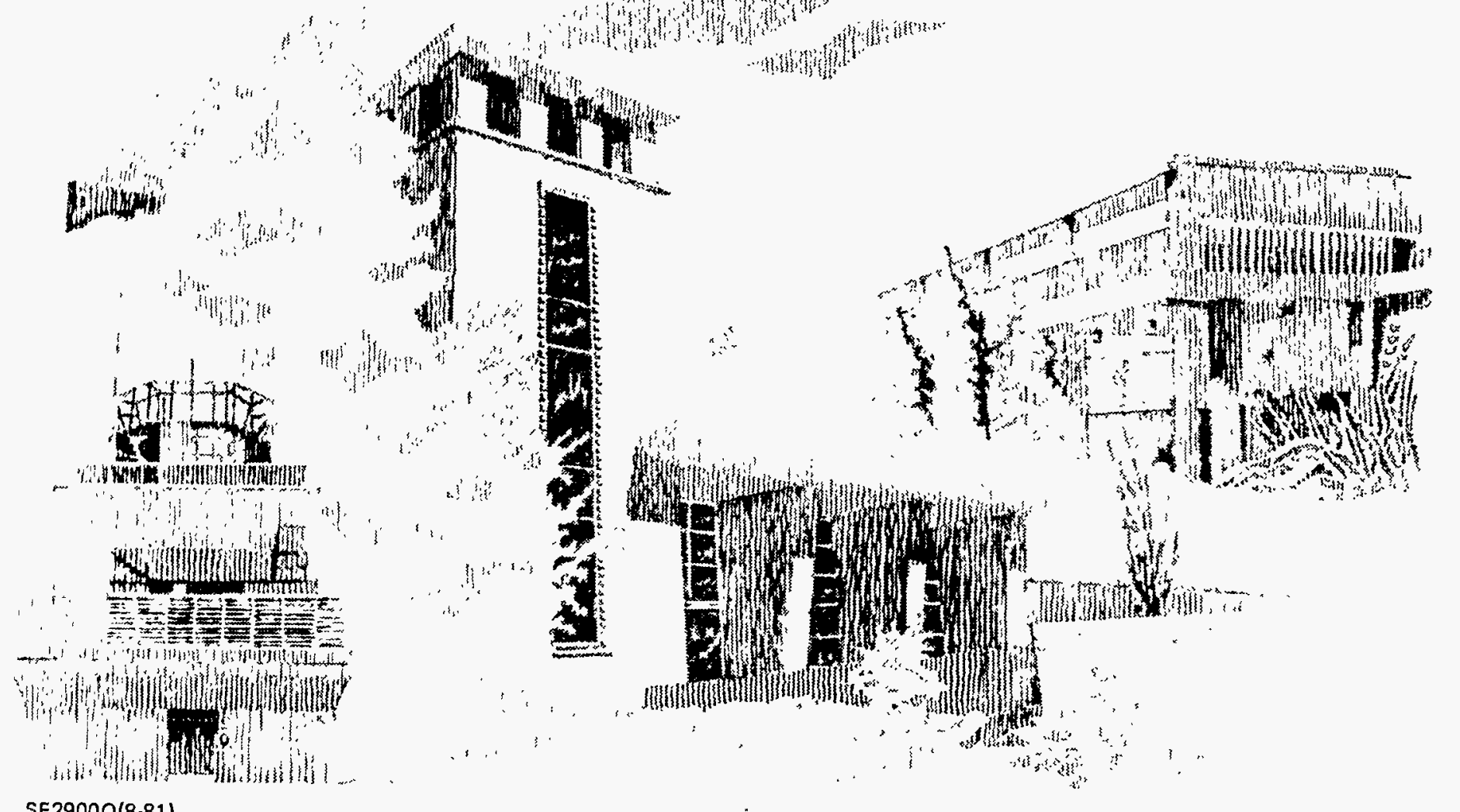


Issued by Sandia National Laboratories, operated for the United States Department of Energy by Sandia Corporation.

NOTICE: This report was prepared as an account of work sponsored by an agency of the United States Government. Neither the United States Government nor any agency thereof, nor any of their employees, nor any of their contractors, subcontractors, or their employees, makes any warranty, express or implied, or assumes any legal liability or responsibility for the accuracy, completeness, or usefulness of any information, apparatus, product, or process disclosed, or represents that its use would not infringe privately owned rights. Reference herein to any specific commercial product, process, or service by trade name, trademark, manufacturer, or otherwise, does not necessarily constitute or imply its endorsement, recommendation, or favoring by the United States Government, any agency thereof or any of their contractors or subcontractors. The views and opinions expressed herein do not necessarily state or reflect those of the United States Government, any agency thereof or any of their contractors.

Printed in the United States of America. This report has been reproduced directly from the best available copy.

Available to DOE and DOE contractors from

Office of Scientific and Technical Information

PO Box 62

Oak Ridge, TN 37831

Prices available from (615) 576-8401, FTS 626-8401

Available to the public from

National Technical Information Service

US Department of Commerce

5285 Port Royal Rd

Springfield, VA 22161

NTIS price codes

Printed copy: A04

Microfiche copy: A01 


\title{
A Viscoplastic Theory for Braze Alloys
}

\author{
M. K. Neilsen, S.N. Burchett, and C.M. Stone \\ Engineering and Manufacturing Mechanics Department \\ J. J. Stephens \\ Mechanical and Corrosion Metallurgy Department \\ Sandia National Laboratories \\ Albuquerque, New Mexico 87185
}

\begin{abstract}
A new viscoplastic theory for CusilABA and other braze alloys has been developed. Like previous viscoplastic theories, this new theory uses a hyperbolic sine function of effective stress in its kinetic equation for the inelastic strain rate. This new theory has an internal state variable which accounts for isotropic hardening and recovery and a second-order, internal state tensor which accounts for kinematic hardening and recovery. Unlike previous theories, the new theory uses evolution equations for the state variables which describe competing mechanisms of power law hardening and static recovery. The evolution equations used in the previous theories describe competing mechanisms of linear hardening, dynamic and static recovery. The new viscoplastic theory was implemented in several finite element codes and used in several metal-to-ceramic brazing simulations. Two approaches for obtaining material parameters for the new viscoplastic theory were developed.
\end{abstract}




\section{Acknowledgments}

The authors would like to acknowledge the assistance of David Schmale, 1832, who conducted the elevated temperature creep compression and uniaxial compression tests on the CusilABA braze alloy. The thorough review of this document by Arlo Fossum, 9117and Tom Buchheit, 1832, was very much appreciated. 


\section{Contents}

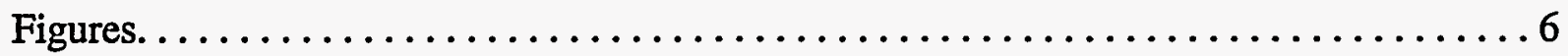

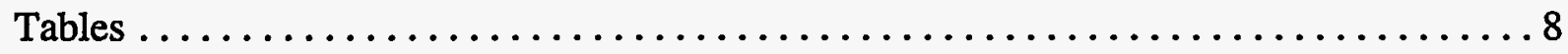

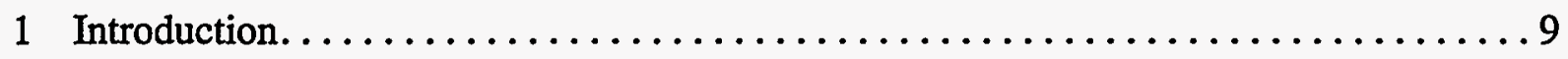

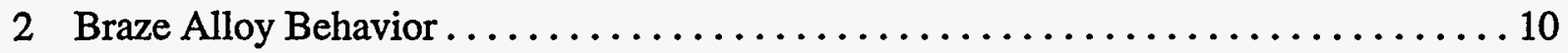

3 Existing Constitutive Theories .............................. 13

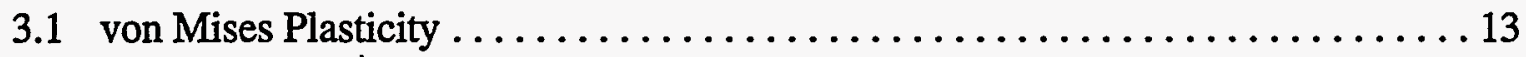

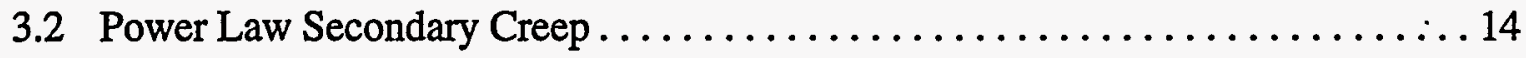

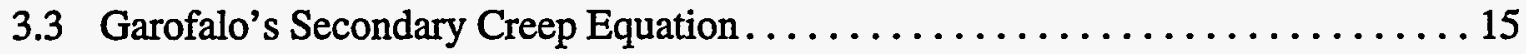

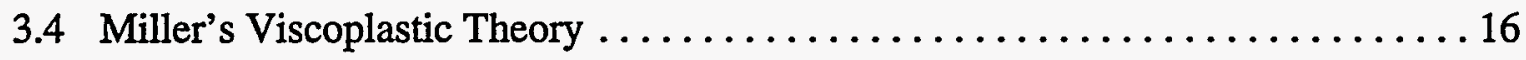

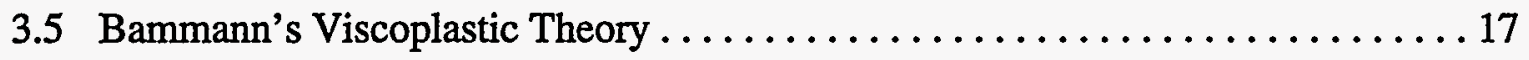

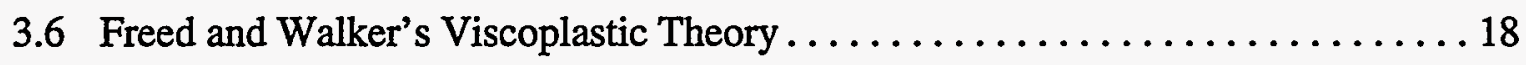

3.7 Review of the Existing Viscoplastic Theories . . . . . . . . . . . . . . 19

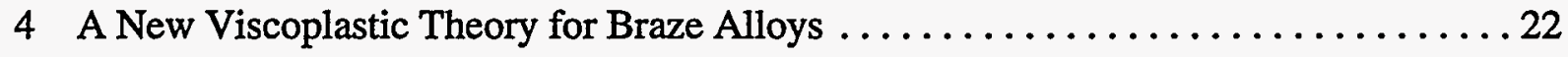

5 Numerical Integration of the New Theory $\ldots \ldots \ldots \ldots \ldots \ldots \ldots \ldots \ldots \ldots \ldots \ldots \ldots \ldots \ldots$

6 Selection of Viscoplastic Material Parameters for CusilABA ............... 25

7 Simulation of Material Characterization Tests for CusilABA $\ldots \ldots \ldots \ldots \ldots \ldots . \ldots 33$

8 Numerical Simulation of Metal-to-Ceramic Brazing . . . . . . . . . . . . . . 40

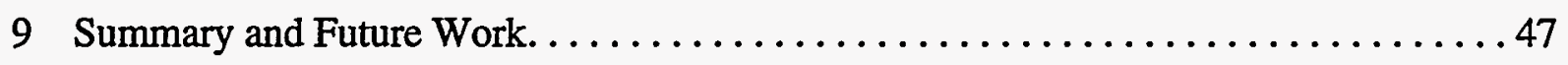

References.................................... 48

Appendix A - Material Parameter Names Used in JAC2D and JAS3D . . . . . . . . . 50

Appendix B - Development of Critical Time Step Size Criteria ............... 53 


\section{Figures}

1. Uniaxial Compression Test Results - CusilABA (Stephens et al., 1993). … . 10

2. Creep Compression Test Results - CusilABA, $350^{\circ} \mathrm{C}$ (Stephens et al., 1993). . . 11

3. Creep Compression Test Results - CusilABA, $650^{\circ} \mathrm{C}$ (Stephens et al., 1993). ...11

4. Minimum Creep Rate Correlations - CusilABA (Stephens et al., 1993). ... . . 12

5. Comparison of Experimental Secondary Creep Data for CusilABA with Behavior Predicted Using a vonMises Plasticity Theory (Solid Lines). $\quad \ldots \ldots \ldots \ldots \ldots 13$

6. Comparison of Experimental Creep Data for CusilABA with Behavior Predicted Using a Power Law Secondary Creep Theory (Solid Lines). $\quad \ldots \ldots \ldots \ldots \ldots 14$

7. Comparison of Experimental Creep Data for CusilABA with Behavior Predicted Using Garofalo's Hyperbolic sine Equation (Solid Lines). $\quad \ldots \ldots \ldots \ldots \ldots \ldots$

8. Effect of Variations in the Internal State Variable $k$ on the Inelastic Strain Rate Predictions Generated by Bammann's Viscoplastic Theory. $\ldots \ldots \ldots \ldots \ldots 20$

9. Effect of Variations in the Internal State Variable D on the Inelastic Strain Rate Predictions Generated by Miller's or Freed and Walker's Viscoplastic Theories. $\quad .21$

10. Selection of Material Parameters $p$ and $f$ from manual fitting process. $\ldots \ldots \ldots 28$

11. Temperature Dependence of Material Parameter - $p$. $\ldots \ldots \ldots \ldots \ldots \ldots \ldots 28$

12. Temperature Dependence of Material Parameter $-\mathrm{f}$. $\quad \ldots \ldots \ldots \ldots \ldots \ldots \ldots . \ldots . \ldots .29$

13. Comparison of Uniaxial Response Predicted Using Various Values for Material Parameters A1 and A3 With the Experimental Results. $\quad \ldots \ldots \ldots \ldots \ldots . \ldots 30$

14. Comparison of Uniaxial Response Predicted Using Various Values for Material

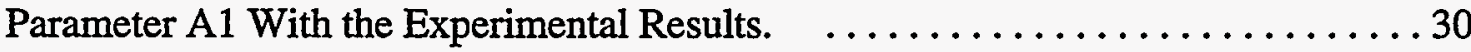

15. Axisymmetric Finite Element Models Used to Simulate the Uniaxial and Creep

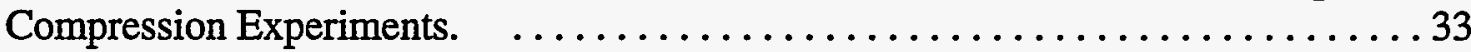

16. Uniaxial Compression Simulations Compared with Experiments on CusilABA, Material Parameters from Manual Fitting Process - Table 2. $\ldots \ldots \ldots \ldots \ldots \ldots \ldots . \ldots . \ldots \ldots$

17. Uniaxial Compression Simulations Compared with Experiments on CusilABA, Simulations Performed Using Isotropic Hardening / Recovery - Table 3. . . . . 34

18. Uniaxial Compression Simulations Compared with Experiments on CusilABA, Simulations Performed Using Kinematic Hardening / Recovery - Table 4. .... 35

19. Simulations of a Room-Temperature, Cyclic Uniaxial Test with Material Parameters from Tables 3 and 4. 
20. Creep Compression Simulations Compared with Experiments at $250^{\circ} \mathrm{C}$. $\ldots \ldots 37$

21. Creep Compression Simulations Compared with Experiments at $350^{\circ} \mathrm{C} . \quad \ldots \ldots 37$

22. Creep Compression Simulations Compared with Experiments at $450^{\circ} \mathrm{C} . \quad \ldots \ldots 38$

23. Creep Compression Simulations Compared with Experiments at $550^{\circ} \mathrm{C}$. $\ldots \ldots 38$

24. Creep Compression Simulations Compared with Experiments at $650^{\circ} \mathrm{C}$. $\ldots . .39$

25. Creep Compression Simulations Compared with Experiments at $748{ }^{\circ} \mathrm{C} . \quad \ldots \ldots 39$

26. Axisymmetric Finite Element Model of an Alumina Ceramic Rod Brazed to a

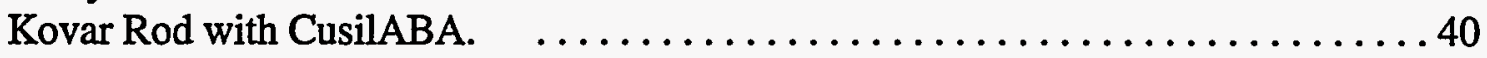

27. Linearized Thermal Expansion Properties of the Braze Joint Materials Used to Generate the Results Shown in Figures 28 through 30.

28. Maximum Principal Stress Distribution Generated in the Alumina Ceramic and Kovar Using Linearized Thermal Expansion of Joint Materials. $\quad \ldots \ldots \ldots \ldots \ldots 43$

29. Effect of Braze Modeling Variations on the Maximum Principal Stress History for Element 600 - Linearized Thermal Expansion of Joint Materials.

30. Effect of Braze Material Parameter Variations on the Maximum Principal Stress History for Element 600 - Linear Thermal Expansion of Joint Materials. . . . . 44

31. Actual Thermal Expansion Properties of the Braze Joint Materials. ......... 44

32. Maximum Principal Stress Distribution Generated in the Alumina Ceramic and Kovar Using Actual Thermal Expansion of Joint Materials. $\quad \ldots \ldots \ldots \ldots \ldots . \ldots 45$

33. Effect of Braze Modeling Variations on the Maximum Principal Stress History for Element 600 - Actual Thermal Expansion of Joint Materials. . ..........46

34. Effect of Braze Material Parameter Variations on the Maximum Principal Stress History for Element 600 - Actual Thermal Expansion of Joint Materials. . . . . . 46 


\section{Tables}

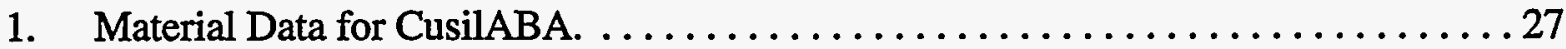

2. Material Parameters for CusilABA - Manual Fitting Process. . . . . . . . . . 31

3. Material Parameters for CusilABA - Isotropic Hardening / Recovery . . . . . . . . 32

4. Material Parameters for CusilABA - Kinematic Hardening / Recovery . . . . . . . . 32

5. Material Parameters for CusilABA (vonMises Plasticity and Power Law Creep) . . . 41

6. Material Parameters for Kovar and Alumina Ceramic ...............41

A1. Material Parameters Used in the JAC2D Implementation . . . . . . . . . . 50

A2. State Variables Used in the JAC2D Implementation . . . . . . . . . . . . 50

A3. Material Parameters Used in the JAS3D Implementation . . . . . . . . . . 51

A4. State Variables Used in the JAS3D Implementation . . . . . . . . . . . . 52 


\section{Introduction}

Ceramic parts are being used more extensively in high-temperature applications due to their superior strength and wear properties compared with metals. Alumina ceramics are also used in a number of important high-voltage, vacuum, electronic components at Sandia National Laboratories. However, when ceramic parts are used there is often a need to join the ceramic part to a metal part. One of the most reliable joining methods is metal-to-ceramic brazing. During a typical metal-to-ceramic brazing process residual stresses are generated due to the differential thermal expansion of the ceramic, metal, and braze alloy. The residual stress level generated during the process depends primarily on the braze joint geometry, the temperature cool-down profile, and the response of the braze joint materials (Stephens et al., 1993). The effects of variations in joint geometry, materials, or cool-down profile can be investigated using finite element analyses. However, the accuracy of these analyses is critically dependent on the validity of the constitutive theories used to describe the behavior of the braze joint materials. In this report, we develop a new viscoplastic theory for braze alloys.

The new theory is similar to existing viscoplastic theories (Miller, 1976; Bammann, 1990; Freed and Walker, 1993) in many respects. All of these viscoplastic theories use a hyperbolic sine function of effective stress in their kinetic equations for the inelastic strain rate. Also, all of these theories have an internal state variable to describe isotropic hardening and recovery and a second-order internal state tensor to describe kinematic hardening and recovery. However, there are two significant differences between the new theory and the existing theories. First, in their evolution equations for the state variables, the previous viscoplastic theories describe competing mechanisms of linear hardening, dynamic recovery, and static or thermal recovery. A close examination of the experimental uniaxial compression data for CusilABA revealed that these experiments could be more accurately simulated by using evolution equations for the state variables which described competing mechanisms of power law hardening and static recovery. A second difference between the new theory and the previous theories is that in the new theory the exponent of the hyperbolic sine term in the kinetic equation for the inelastic strain rate is a function of the absolute temperature and not a material constant.

This report begins with an experimental investigation into the behavior of an active metal braze alloy, CusilABA (62.2Ag-36.2Cu-1.6Ti). Next, existing constitutive theories for metals are reviewed. None of the existing constitutive theories were able to completely describe the behavior of CusilABA over the temperature range of interest; thus, a new viscoplastic theory for braze alloys was developed. The new viscoplastic theory was implemented in the finite element codes JAC2D (Biffle and Blanford, 1994), and JAS3D (Blanford, 1995). Both manual and automated processes for selecting material parameters for the new constitutive theory are described. Next, the uniaxial compression and creep compression experiments were simulated using the new viscoplastic theory to compare the behavior predicted by the new theory with the experimental data for CusilABA and to evaluate the accuracy of the numerical implementation. Finally, the metal-to-ceramic brazing of an alumina ceramic rod to a metal rod was simulated using existing constitutive theories and the new viscoplastic theory to investigate the effects of braze modeling variations on residual stress predictions. 


\section{Braze Alloy Behavior}

A variety of braze alloys have been characterized at Sandia National Laboratories with uniaxial compression and creep compression experiments (Stephens et al., 1993). Results from uniaxial compression experiments on CusilABA (62.2Ag-36.2Cu-1.6Ti) are shown in Figure 1. These experiments were performed using a constant true strain rate of $1.65 \times 10^{-4} \mathrm{~s}^{-1}$. The yield strength of CusilABA decreases significantly as the test temperature is increased. Furthermore, the amount of strain hardening also decreases with increases in the test temperature.

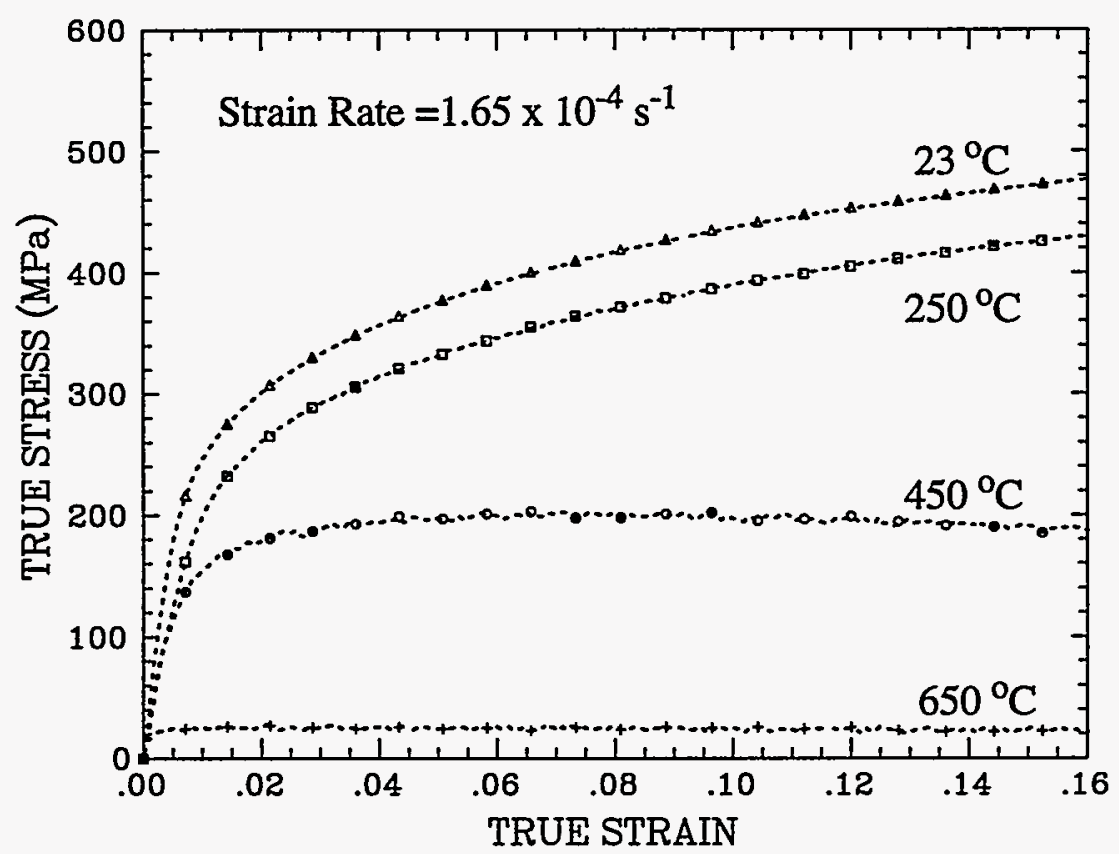

Figure 1. Uniaxial Compression Test Results - CusilABA (Stephens et al., 1993).

Typical creep compression test results for fixed temperatures of $350^{\circ} \mathrm{C}$ and $650^{\circ} \mathrm{C}$ are shown in Figures 2 and 3. During these tests, the load was ramped to a prescribed value in approximately 18 seconds and then held constant for the duration of the test. The numbers in Figures 2 and 3 represent the applied load divided by the original cross-sectional area of the specimen. During the $350^{\circ} \mathrm{C}$ tests, the material exhibits an initial creep rate that is significantly higher than the secondary or minimum creep rate that is reached later in the test. This dramatic change in strain rate occurs while the sample temperature and the stress applied to the sample are nearly constant; thus, the inelastic strain rate must depend on some other variable which is changing during the $350^{\circ} \mathrm{C}$ test. This third variable which cannot be directly measured or controlled is an internal state variable which defines the current state of the braze alloy. Changes in the inelastic strain rate indicate that the state of the material is changing during the $350{ }^{\circ} \mathrm{C}$ creep compression tests. During the higher temperature $650{ }^{\circ} \mathrm{C}$ tests, the material exhibits an inelastic strain rate that is nearly constant (Figure 3 ) which suggests that the state of the material is not changing significantly during these elevated temperature tests. 


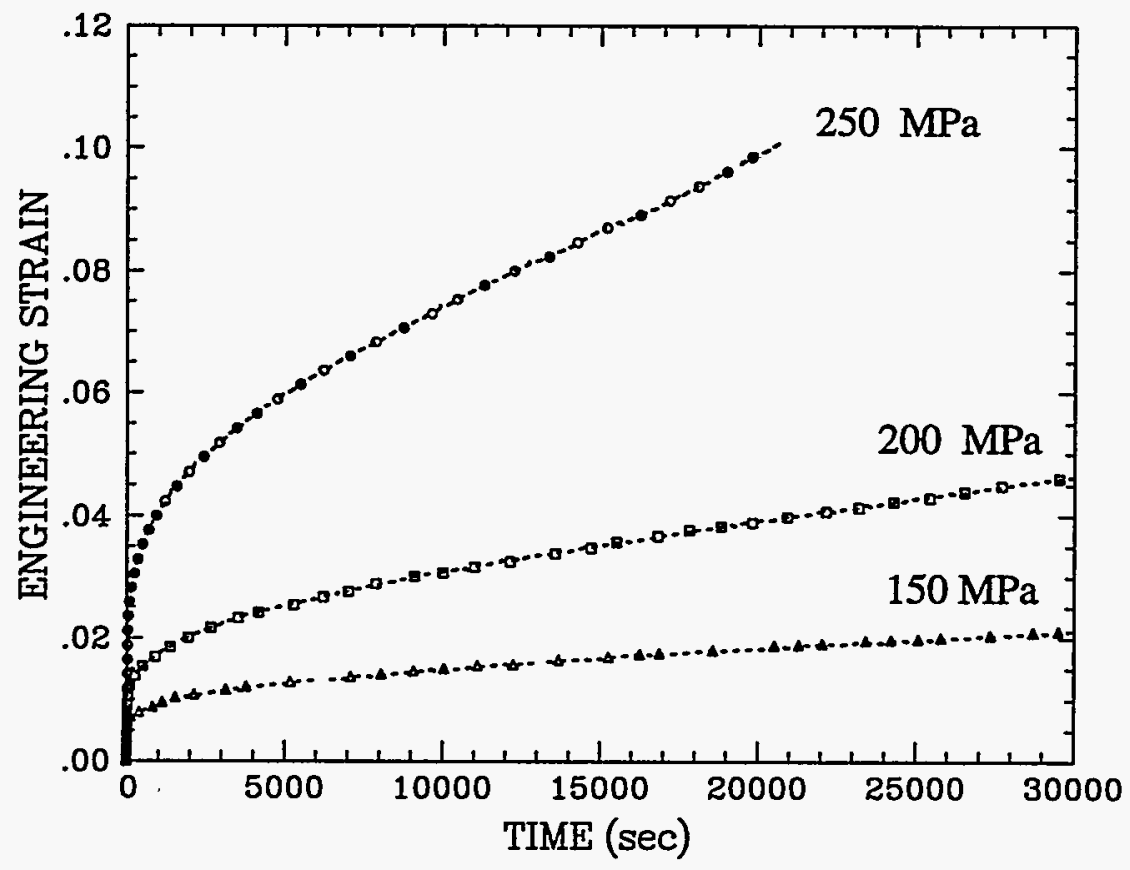

Figure 2. Creep Compression Test Results - CusilABA, $350^{\circ} \mathrm{C}$ (Stephens et al., 1993).

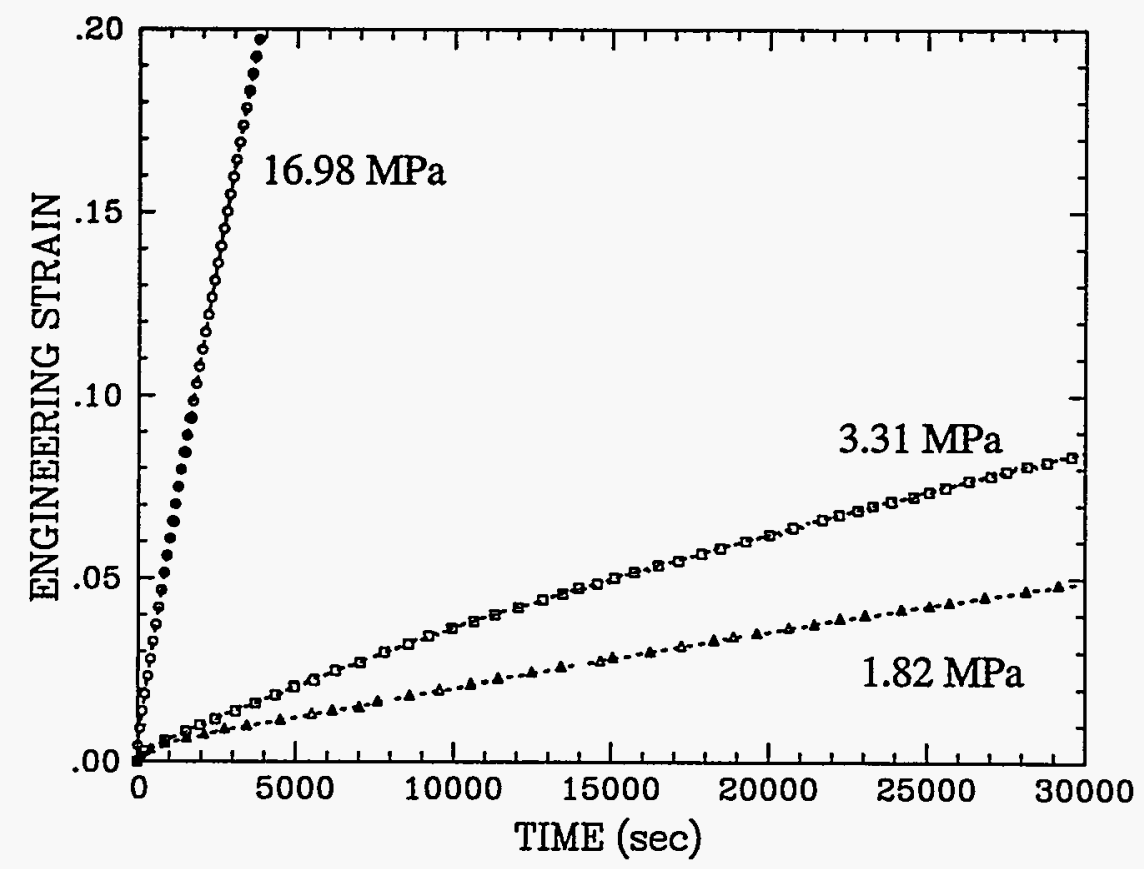

Figure 3. Creep Compression Test Results - CusilABA, $650^{\circ} \mathrm{C}$ (Stephens et al., 1993). 
The secondary or minimum creep rates measured during the creep compression tests are typically plotted as a function of true stress which is calculated from the load/displacement data associated with the point where the minimum creep rate occurred (Figure 4). Each data point represents one creep compression test. The data in Figure 4 clearly show that the secondary creep rate increases with temperature at a constant stress level, and with stress at a constant temperature. Also, the slopes of these curves tend to decrease as the temperature increases.

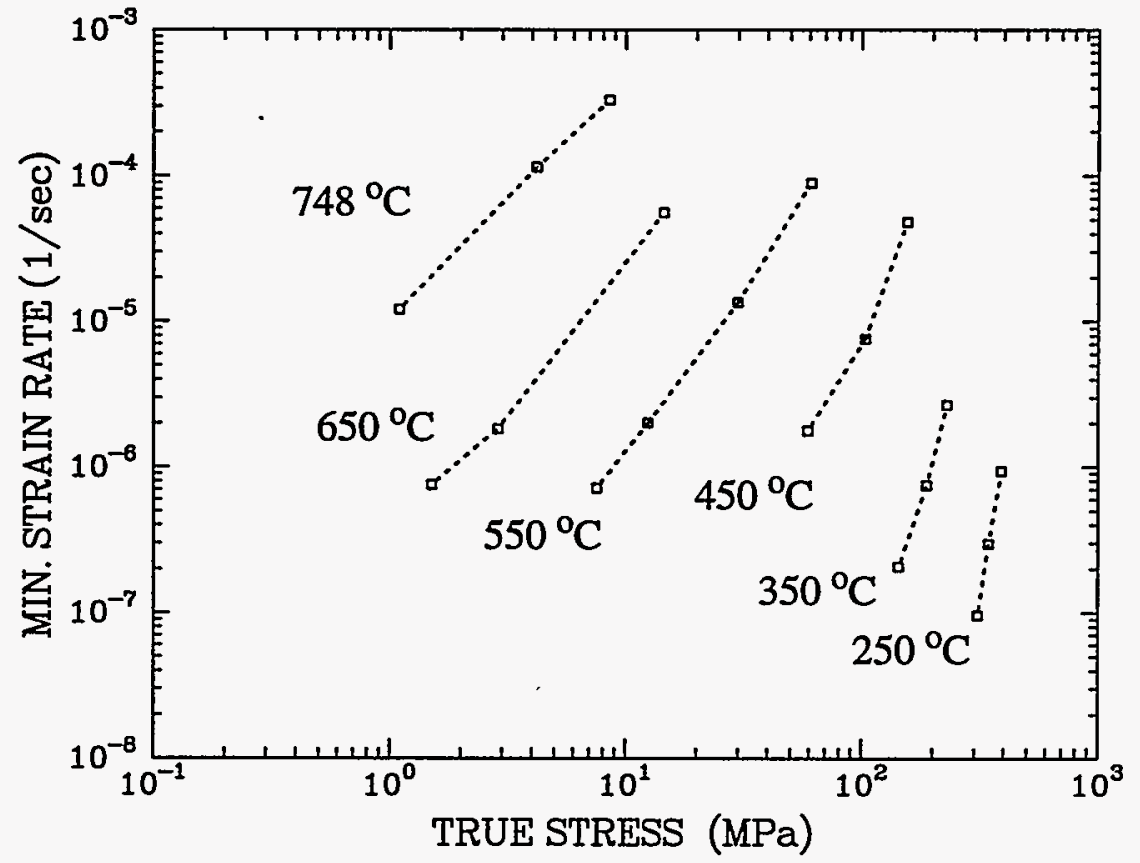

Figure 4. Minimum Creep Rate Correlations - CusilABA (Stephens et al., 1993).

In summary, these experiments clearly show that at temperatures above $450{ }^{\circ} \mathrm{C}$ CusilABA exhibits very little strain hardening during the uniaxial compression tests and creep rates that are nearly constant during the creep compression tests. Thus, the material state is not changing very much during these elevated temperature experiments. At temperatures below $450{ }^{\circ} \mathrm{C}$, CusilABA exhibits a significant amount of strain hardening during the uniaxial compression tests, and significant changes in the creep rate during the creep compression tests. These changes in material response indicate that the state of material is changing significantly during these lower temperature tests. These changes in material state cannot be directly measured but must be inferred from the changes in creep rate, etc. that can be measured. Since the material state changes during some of the creep compression tests before the minimum creep rate is reached, the curves shown in Figure 4 do not represent material with the same current state. Thus, the selection of material parameters for CusilABA is more complicated than simply finding parameters which provide the best fit to the data in Figure 4. This point will be discussed further in Chapter 6. Numerous other braze alloys (e.g. $50 \mathrm{Au}-50 \mathrm{Cu}$ alloy, Palni, $\mathrm{Palco}$, and Cusil) qualitatively exhibit behavior similar to CusilABA. 


\section{Existing Constitutive Theories}

A number of constitutive theories have been developed and implemented in finite element codes to describe the inelastic deformation of metals. This section includes a very brief review of five different theories and a discussion of which braze alloy behaviors are captured by each of these theories. The five constitutive theories reviewed in this section are: (1) vonMises plasticity, (2) Power Law secondary creep, (3) Miller's viscoplasticity, (4) Bammann's viscoplasticity (Sandia Damage), and (5) Freed and Walker's viscoplasticity. A more complete review of existing viscoplastic theories for metals is provided by Miller (1987).

\section{1 von Mises Plasticity}

One of the simplest theories which has been used in brazing simulations is the von Mises plasticity theory (Stephens et al., 1992). The effects of load history and temperature changes on the yield strength can be captured using this simple, time-independent plasticity theory. Also, models based on this theory can be easily integrated using the radial return algorithm. However, this theory assumes that the inelastic deformation is instantaneous when the applied von Mises effective stress exceeds the yield strength of the material. Thus, this theory predicts a material response of vertical lines in the minimum strain rate vs. effective stress space (Figure 5). A simple von Mises plasticity theory is clearly not able to adequately describe the viscoplastic behavior of the CusilABA braze alloy.

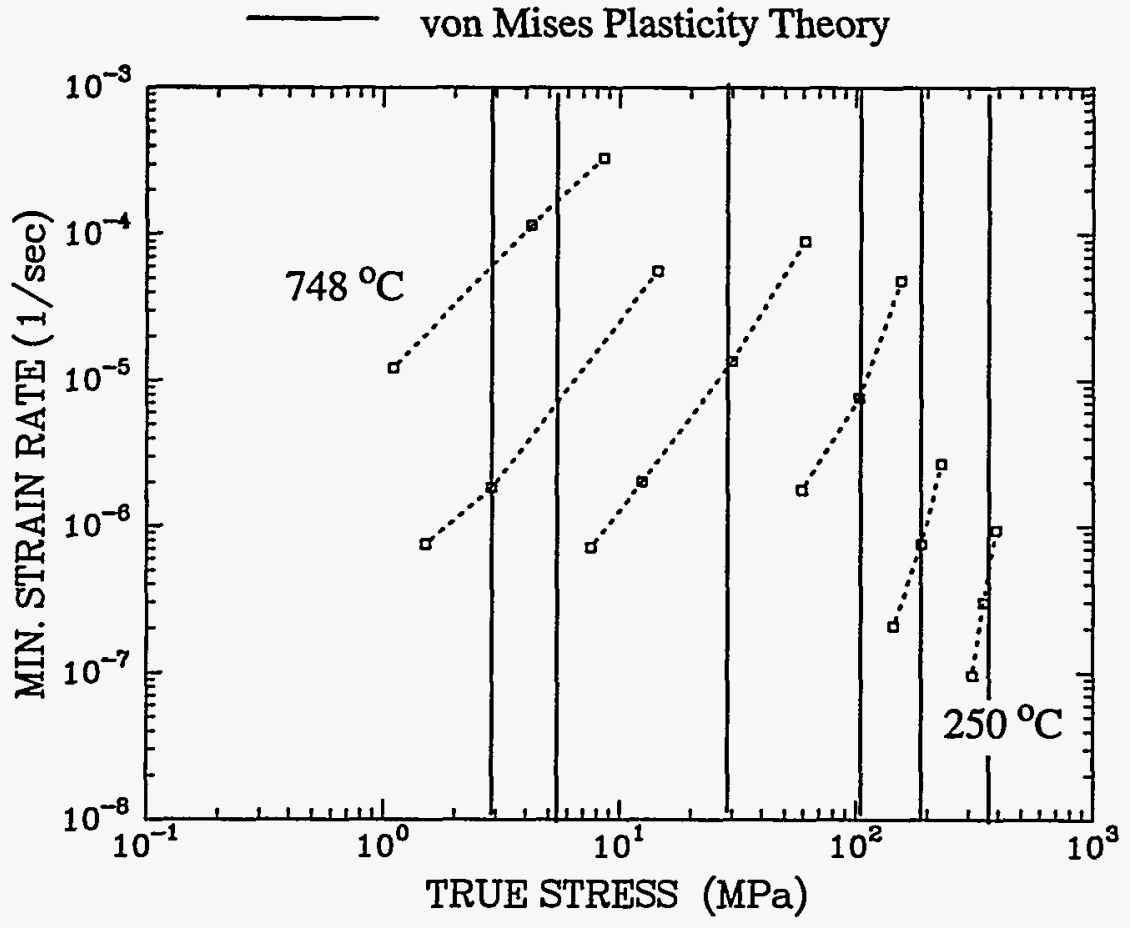

Figure 5. Comparison of Experimental Secondary Creep Data for CusilABA with Behavior Predicted Using a vonMises Plasticity Theory (Solid Lines). 


\subsection{Power Law Secondary Creep}

The power law secondary creep theory has been implemented in many finite element codes. This theory has an inelastic strain rate, $\mathrm{d}^{\text {in }}$, given by

$$
d^{\text {in }}=\frac{3}{2} f \sigma^{p} n
$$

where $f$ is a scalar function of the absolute temperature, $\sigma$ is the von Mises effective stress, $p$ is a material parameter, and $\mathbf{n}$ is the normalized deviatoric stress tensor which is equal to the deviatoric stress tensor divided by the vonMises effective stress. Models based on this theory are efficiently integrated using either an approximate analytical solution (Krieg, 1983) or a forward Euler method with adaptive time step size selection (Stone and Morgan, 1989). A fit of this theory to the experimental data from the creep-compression tests obtained by Stephens et al. (1993) is shown in Figure 6. The power law secondary creep theory predicts a material response of straight lines in the minimum strain rate vs. effective stress space. This theory accurately describes the creep response of the material subjected to relatively low effective stress levels at temperatures of 550,650 , and $748{ }^{\circ} \mathrm{C}$. However, at relatively high effective stress levels the minimum strain rate can no longer be adequately described using the power law secondary creep theory. This failure of the power-law creep theory is commonly referred to as "power-law breakdown". Notice that the material response observed experimentally approaches the behavior predicted by the von Mises plasticity theory for relatively high effective stress levels and low temperatures.

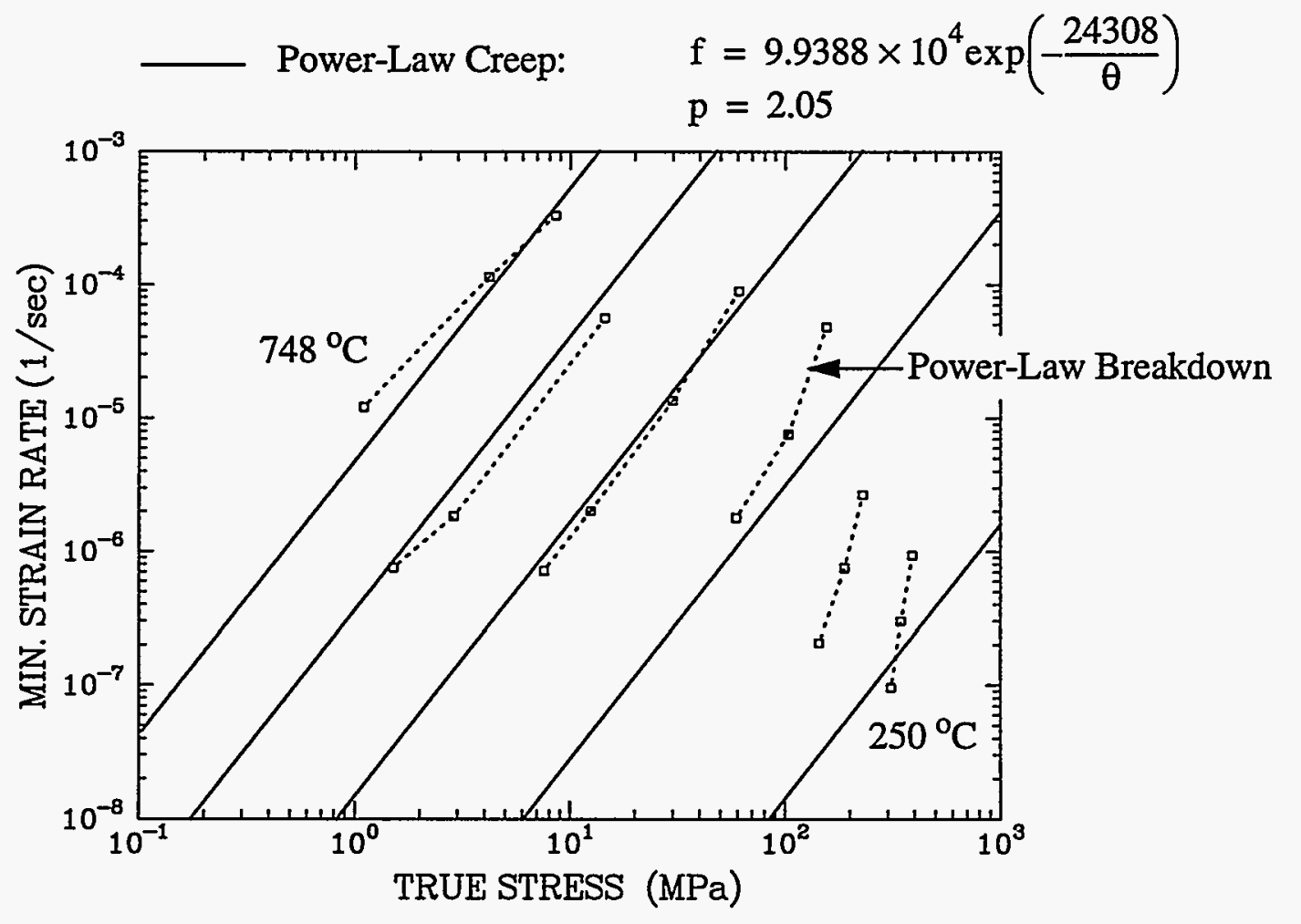

Figure 6. Comparison of Experimental Creep Data for CusilABA with Behavior Predicted Using a Power Law Secondary Creep Theory (Solid Lines). 


\subsection{Garofalo's Secondary Creep Equation}

Garofalo (1965) showed that the minimum or secondary creep rate exhibited by many metals could be described using a hyperbolic sine function as follows

$$
\mathrm{d}^{\text {in }}=\frac{3}{2} f \sinh ^{\mathrm{p}}\left(\frac{\sigma}{\mathrm{c}}\right) \mathrm{n}
$$

where $d^{\text {in }}$ is the inelastic strain rate, $f$ is a scalar function of the absolute temperature, $\sigma$ is the von Mises effective stress, $p$ and $c$ are material parameters, and $\mathbf{n}$ is the normalized deviatoric stress tensor. A fit of this equation to the experimental data from the creep compression tests on CusilABA obtained by Stephens et al. (1993) is shown in Figure 7. Garofalo's hyperbolic sine equation captures both the power-law secondary creep behavior at low effective stress levels and the power-law breakdown at higher effective stress levels. However, this equation by itself cannot describe the primary creep which is exhibited early in the creep compression tests or the strain-hardening exhibited during the uniaxial compression tests (Figure 1). Three different viscoplastic theories which capture both hardening and recovery and use Garofalo's equation as a starting point are briefly described in the next three sections.

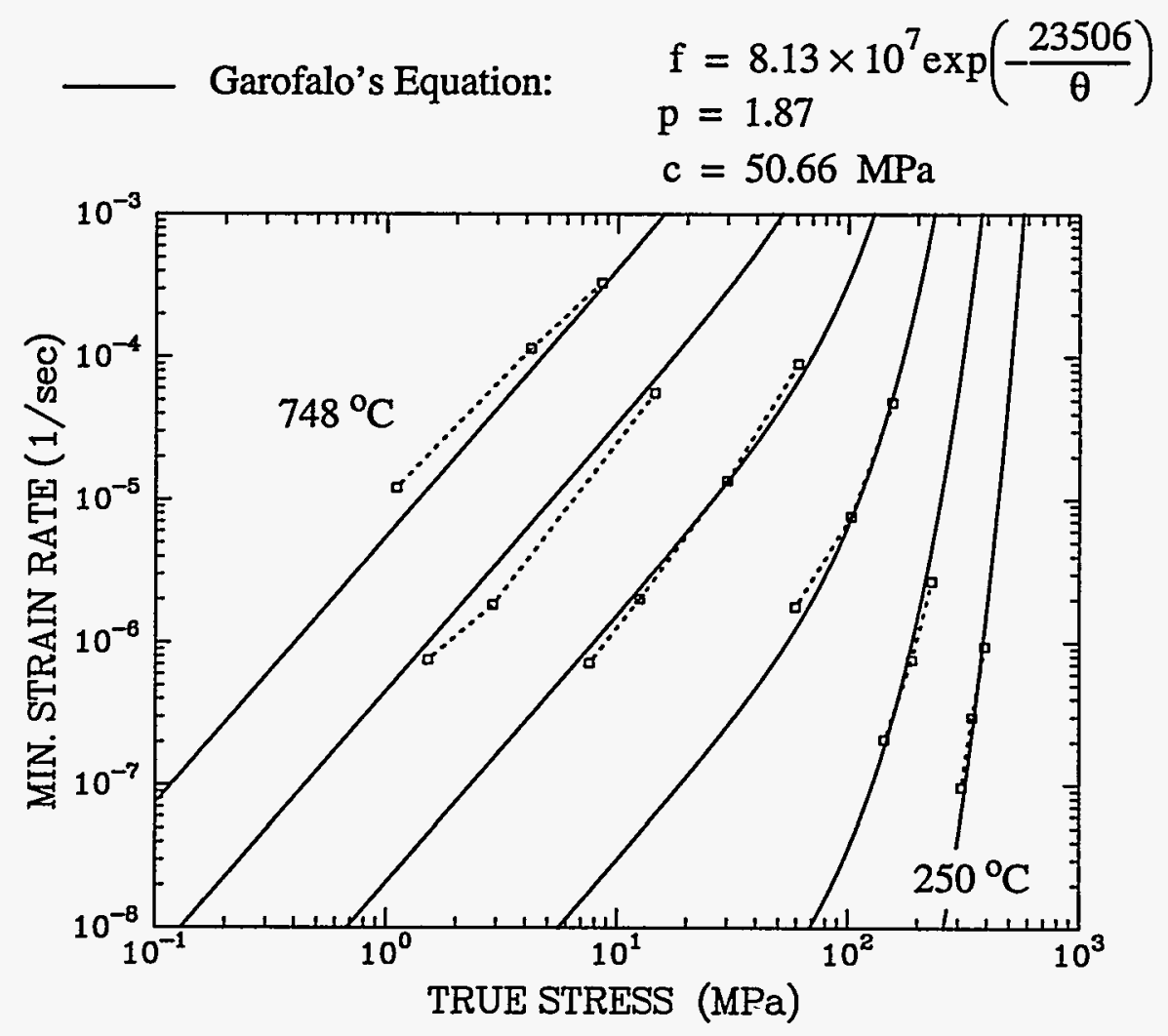

Figure 7. Comparison of Experimental Creep Data for CusilABA with Behavior Predicted Using Garofalo's Hyperbolic sine Equation (Solid Lines). 


\subsection{Miller's Viscoplastic Theory}

A viscoplastic theory for metals was developed by Miller (1976) using Garofalo's hyperbolic sine equation as a starting point. This theory has a kinetic equation for the inelastic strain rate, $\mathbf{d}^{\text {in }}$, which is as follows

$$
d^{\text {in }}=\gamma n=f \sinh ^{p}\left(\left(\frac{\tau}{D}\right)^{1.5}\right) n
$$

where $\gamma$ is the magnitude of the inelastic rate, $f$ is a scalar function of the absolute temperature, $\mathrm{p}$ is a material parameter, and $\mathrm{D}$ is an internal state variable. The second-order tensor $\mathbf{n}$ is the normalized stress difference tensor,

$$
\mathbf{n}=\frac{\mathbf{s}-\mathbf{B}}{\tau}
$$

where $\mathbf{s}$ is the stress deviator and $\mathbf{B}$ is an internal state tensor which is commonly referred to as the backstress. The magnitude of the stress difference, $\tau$, given by

$$
\tau=\sqrt{\frac{3}{2}(\mathbf{s}-\mathbf{B}):(\mathbf{s}-\mathbf{B})}
$$

The temperature dependence is described using a scalar function $\mathrm{f}$ which is as follows

$$
f=\left(\begin{array}{cc}
\operatorname{Cexp}\left(\left[\left(\frac{-Q}{k \theta_{\mathrm{tr}}}\right)\right] \cdot\left[1+\ln \left(\frac{\theta_{\mathrm{tr}}}{\theta}\right)\right]\right) & \text { for } \theta \leq \theta_{\mathrm{tr}} \\
\operatorname{Cexp}\left(\frac{-\mathrm{Q}}{\mathrm{k} \theta}\right) & \text { for } \theta>\theta_{\mathrm{tr}}
\end{array}\right.
$$

where $\theta$ is the absolute temperature, $\theta_{t r}$ is the transition temperature between regimes in which different deformation mechanisms with different activation energies are controlling. Evolution of the internal state tensor, $\mathbf{B}$, is given by

$$
\dot{\mathbf{B}}=\mathrm{H}_{1} \mathbf{d}^{\mathrm{in}}-\mathrm{H}_{1} \mathrm{f} \sinh ^{\mathrm{p}}\left(\mathrm{A}_{1} \mathrm{~B}\right) \frac{\mathbf{B}}{\mathrm{B}}
$$

where $B$ is the magnitude of $B$. Evolution of the internal state variable, D, is given by

$$
\dot{D}=H_{2} \gamma-H_{2} f \sinh ^{p}\left(A_{2} D^{3}\right)
$$

where $\mathrm{H}_{2}$ is as follows

$$
\mathrm{H}_{2}=\mathrm{A}_{4}\left[\mathrm{~A}_{3}+\mathrm{B}-\frac{\mathrm{A}_{2}}{\mathrm{~A}_{1}} \mathrm{D}^{3}\right]
$$

and $C, H_{1}, A_{1}, A_{2}, A_{3}$, and $A_{4}$ are material parameters. In this theory, the state variable, $D$, is introduced to describe isotropic strain hardening and recovery. The state tensor, $\mathbf{B}$, is introduced to describe kinematic strain hardening and recovery. 


\subsection{Bammann's Viscoplastic Theory}

The viscoplastic theory developed by Bammann (1990) was combined with a scalar damage theory to create the Sandia Damage theory. This theory was originally developed to describe the behavior of metals subjected to very high strain rates. Like Miller's theory, Bammann's viscoplastic theory uses a hyperbolic sine function in its kinetic equation for the inelastic strain rate. This theory has an inelastic strain rate, $d^{\text {in }}$, given by

$$
\mathbf{d}^{\text {in }}=\gamma \mathbf{n}=\mathrm{f} \sinh \left(\frac{\tau-\mathrm{k}-\mathrm{Y}}{\mathrm{V}}\right) \mathrm{n}
$$

where $\gamma$ is the magnitude of the inelastic rate, $V, Y$, and $f$ are scalar functions of the absolute temperature, $\tau$ is the magnitude of the stress difference (Equation 5), $\mathrm{k}$ is an internal state variable, and $\mathbf{n}$ is the normalized stress difference tensor given by Equation 4 . With this theory, the temperature dependence in the kinetic equation for the inelastic strain rate is represented by the scalar functions $\mathrm{V}, \mathrm{Y}$, and $\mathrm{f}$ which can be written as follows

$$
\begin{gathered}
V=C_{1} \exp \left(-\frac{C_{2}}{\theta}\right) \\
Y=C_{3} \exp \left(\frac{C_{4}}{\theta}\right) \\
f=C_{5} \exp \left(-\frac{C_{6}}{\theta}\right)
\end{gathered}
$$

Evolution of the internal state tensor, $\mathbf{B}$, is given by

$$
\dot{B}=h d^{\text {in }}-\left[r_{d} \gamma+r_{s}\right] B B
$$

and evolution of the internal state variable, $k$, is given by

$$
\dot{\mathrm{k}}=\mathrm{H} \gamma-\left[\mathrm{R}_{\mathrm{d}} \gamma+\mathrm{R}_{\mathrm{s}}\right] \mathrm{k}^{2}
$$

where $B$ is the magnitude of $B$, and $h, r_{d}, r_{s}, H, R_{d}$, and $R_{s}$ are Arrhenius functions of the absolute temperature, $\theta$, similar to $f$

$$
\begin{array}{rr}
\mathrm{h}=\mathrm{C}_{9} \exp \left(\frac{\mathrm{C}_{10}}{\theta}\right) & \mathrm{H}=\mathrm{C}_{15} \exp \left(\frac{\mathrm{C}_{16}}{\theta}\right) \\
\mathrm{r}_{\mathrm{d}}=\mathrm{C}_{7} \exp \left(-\frac{\mathrm{C}_{8}}{\theta}\right) & \mathrm{R}_{\mathrm{d}}=\mathrm{C}_{13} \exp \left(-\frac{\mathrm{C}_{14}}{\theta}\right) \\
\mathrm{r}_{\mathrm{s}}=\mathrm{C}_{11} \exp \left(-\frac{\mathrm{C}_{12}}{\theta}\right) & \mathrm{R}_{\mathrm{s}}=\mathrm{C}_{17} \exp \left(-\frac{\mathrm{C}_{18}}{\theta}\right)
\end{array}
$$

and $\mathrm{C}_{1}$ through $\mathrm{C}_{18}$ are material parameters. 


\subsection{Freed and Walker's Viscoplastic Theory}

A coupled viscoplastic / plastic theory for metals was also developed by Freed and Walker (1993). In the viscoplastic regime, this theory uses a hyperbolic sine function in its kinetic equation for the inelastic strain rate, $d^{\text {in }}$, which is as follows

$$
d^{\text {in }}=\gamma \mathbf{n}=f \sinh ^{p}\left(\frac{\tau}{D}\right) \mathbf{n}
$$

where $f$ is a scalar function of the absolute temperature, $p$ is a material parameter, $D$ is an internal state variable, $\tau$ is the magnitude of the stress difference (Equation 5 ), and $\mathbf{n}$ is again the normalized stress difference tensor given by Equation 4 . With this theory, all of the temperature dependence is represented by a scalar function $\mathrm{f}$ which is identical to the function used by Miller (Equation 6).

For this theory, the back stress, $\mathbf{B}$, is taken to be the sum of two individual back stresses as follows

$$
\mathbf{B}=\mathbf{B}_{\mathrm{s}}+\mathbf{B}_{1}
$$

where $\mathbf{B}_{\mathrm{s}}$ is the short range back stress and $\mathbf{B}_{1}$ is the long range back stress. The evolution equations for the second-order back stress tensors have the following form

$$
\dot{\mathbf{B}}_{\mathrm{s}}=2 \mathrm{H}_{\mathrm{s}} \mathrm{d}^{\mathrm{in}}-\mathrm{R}_{\mathrm{s}} \gamma \mathbf{B}_{\mathrm{s}}
$$

and

$$
\dot{\mathrm{B}}_{1}=2 \mathrm{H}_{1} \mathrm{~d}^{\mathrm{in}}-\mathrm{R}_{1} \gamma \mathbf{B}_{1}
$$

where $H_{s}, R_{s}, H_{1}$, and $R_{1}$ are material parameters. The evolution of the internal state variable, $D$, is given by

$$
\dot{\mathrm{D}}=\mathrm{H}_{2} \gamma-\mathrm{Af} \sinh ^{\mathrm{p}}\left(\frac{\mathrm{D}-\mathrm{D}_{0}}{\delta \mathrm{C}}\right)
$$

where $\mathrm{H}_{2}, \mathrm{~A}, \mathrm{p}, \delta$, and $\mathrm{C}$ are material parameters, and $\mathrm{D}_{0}$ represents a reference or minimum value for state variable $D$.

When the applied von Mises effective stress difference exceeds the yield strength of the material, a time-independent, plasticity theory is used to describe the material behavior. In this regime the inelastic deformation is instantaneous and chosen to satisfy the consistency condition for the stress state to remain on the yield surface. Thus, this theory predicts a viscoplastic response for low effective stress levels and a time-independent plastic response for high effective stress levels. 


\subsection{Review of the Existing Viscoplastic Theories}

The three viscoplastic theories presented in the previous sections are similar in several respects. All of these theories use a hyperbolic sine function in their kinetic equations for the inelastic strain rate, Equations 3,10, and 15. Also, all of these theories have an internal state variable which accounts for isotropic hardening / recovery, and a second-order internal state tensor which accounts for kinematic hardening / recovery. However, there are some significant differences between these theories.

In Miller's and Freed and Walker's kinetic equations for the inelastic strain rate, Equations 3 and 15, the hyperbolic sine function is raised to a power $p$, but in Bammann's kinetic equation the hyperbolic sine function is not raised to a power. Material parameter $\mathrm{p}$ depends on the controlling deformation mechanism and is used to define the slope of the inelastic strain rate curves (Figure 7) in the power-law secondary creep regime. Without the exponent p, it will not be possible to match the slope of the braze alloy data in the power-law secondary creep regime.

In Miller's and Freed and Walker's kinetic equations for the inelastic strain rate, Equations 3 and 15 , the state variable which accounts for isotropic strain hardening, D, is in the denominator of the hyperbolic sine term's argument but in Bammann's theory, Equation 10, the state variable which accounts for isotropic strain hardening, $k$, is in the numerator. The significance of this difference is illustrated by the following example. When CusilABA was compressed at room temperature to a total strain of 0.16 , its yield strength increased $260 \mathrm{MPa}$ (Figure 1) which could be captured with Bammann's theory by allowing state variable $k$ to evolve to a value of $260 \mathrm{MPa}$ during this test. Increases in state variable $\mathrm{k}$ will cause all of the inelastic strain rate curves to be shifted the same amount (Figure 8). This implies that if we strain-harden the material at room temperature, the predicted yield strength at every temperature will increase by the same amount. It is unlikely that changes in material state generated during the room temperature uniaxial compression test would cause the material's yield strength at $748^{\circ} \mathrm{C}$ to isotropically increase by $260 \mathrm{MPa}$. In Freed and Walker's theory, the internal state variable $D$ is used to describe the increase in the isotropic yield strength of a material. For example, when CusilABA was compressed at room temperature to a total strain of 0.16 , its yield strength increased by a factor of 2.18 from $220 \mathrm{MPa}$ to $480 \mathrm{MPa}$ (Figure 1) which could be captured by allowing state variable $D$ to increase by a factor of 2.18 during this test. Increases in state variable $D$ will cause all of the inelastic strain rate curves to have their stress values scaled by a factor of $D / D_{0}$ (Figure 9). This implies that if we strain-harden the material at room temperature and increase its strength by a factor of 2.18 , then the material's yield strength at all temperatures will also increase by a factor of 2.18. Again, it is unlikely that the yield strength of the material at elevated temperatures is actually affected this much by changes in material state. One way to avoid this difficulty would be to simply multiply the isotropic state variables $k$ or $D$ by some function of temperature in the kinetic equation for the inelastic strain rate, Equations 3, 10 or 15 . However, additional experiments are needed to fully quantify the effects that changes in material state have on the curves shown in Figure 4.

A new viscoplastic theory which overcomes the shortcomings of the existing viscoplastic theories and more accurately describes the behavior of CusilABA is described in the next section. 

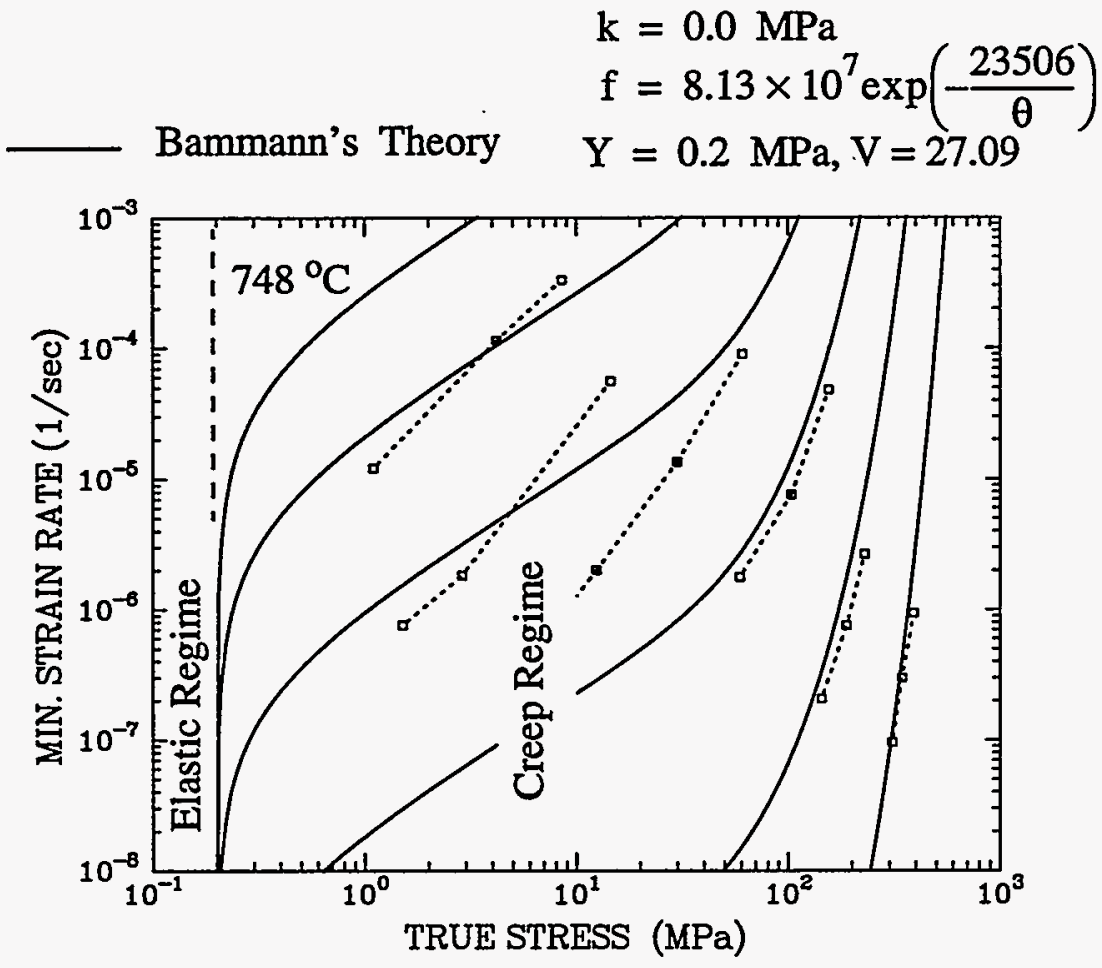

- Bammann's Theory $\mathrm{k}=260.0 \mathrm{MPa}$

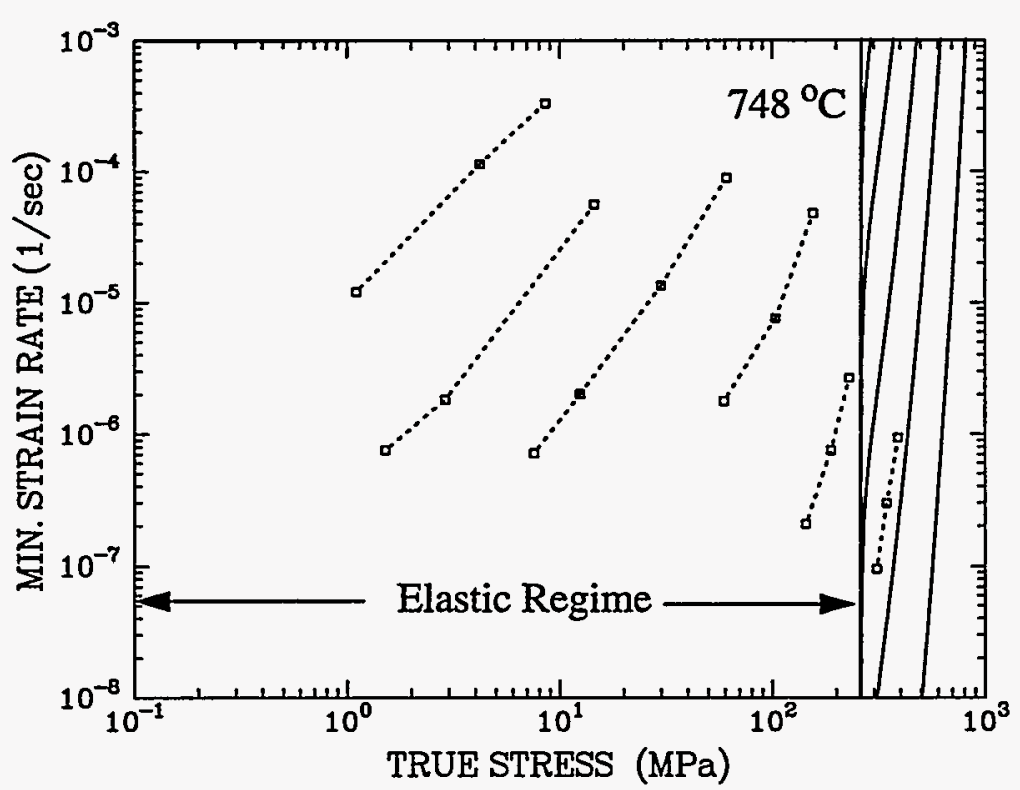

Figure 8. Effect of Variations in the Internal State Variable k on the Inelastic Strain Rate Predictions Generated by Bammann's Viscoplastic Theory. 
_ Freed and Walker's Theory: $\quad \begin{aligned} & \mathrm{D}=50.66 \mathrm{MPa} \\ & \mathrm{f}=8.13 \times 10^{7} \exp \left(-\frac{23506}{\theta}\right) \\ & \mathrm{p}=1.87\end{aligned}$

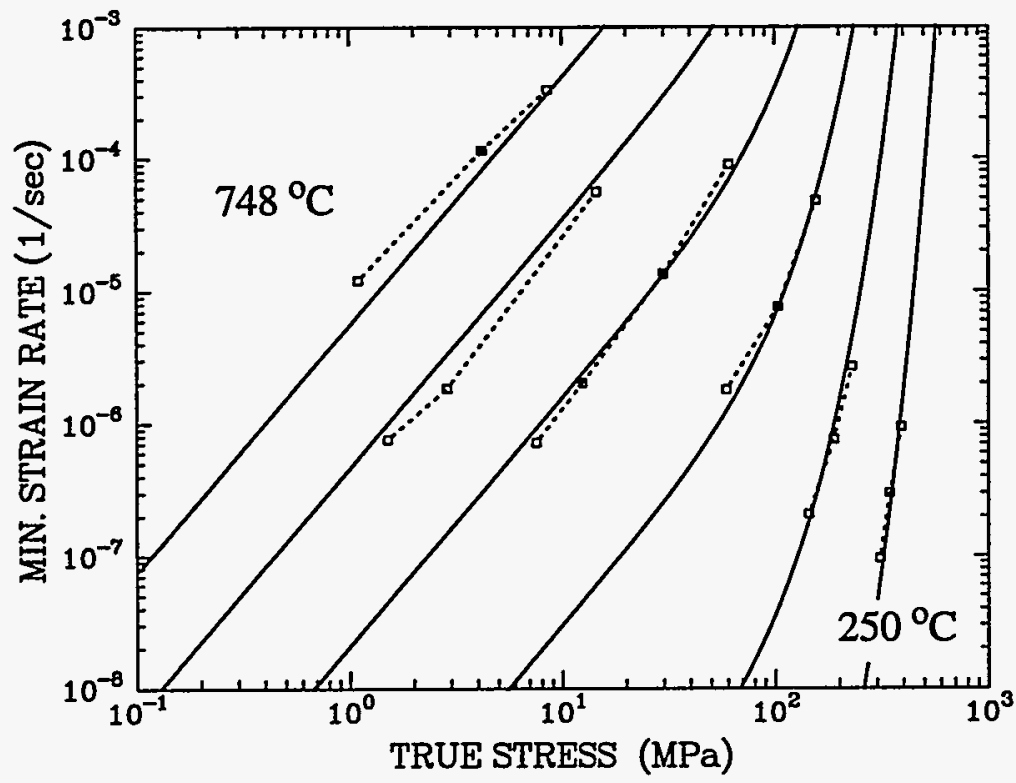

_ Freed and Walker's Theory: $\quad \mathrm{D}=110.4 \mathrm{MPa}$

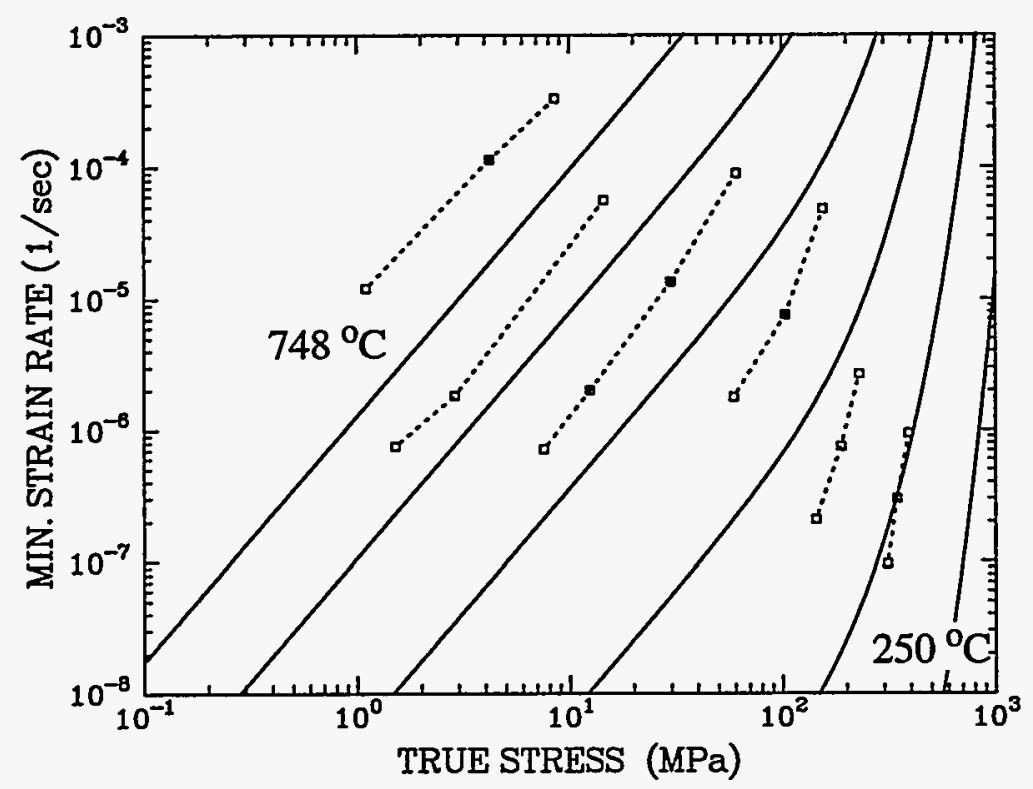

Figure 9. Effect of Variations in the Internal State Variable D on the Inelastic Strain Rate Predictions Generated by Miller's or Freed and Walker's Viscoplastic Theories. 


\section{A New Viscoplastic Theory for Braze Alloys}

The new viscoplastic theory developed in this section is significantly influenced by the theories developed by Miller, Bammann, and Freed and Walker. This new theory uses a kinetic equation for the inelastic strain rate, $d^{\text {in }}$, with the following form

$$
d^{\text {in }}=\frac{3}{2} \gamma \mathbf{n}=\frac{3}{2} f \sinh ^{p}\left(\frac{\tau}{\alpha D}\right) n
$$

where $\gamma$ is the magnitude of the inelastic rate, $f, p$, and $\alpha$ are functions of the absolute temperature, $D$ is an internal state variable, $\mathbf{n}$ is the normalized stress difference tensor which is given by,

$$
\mathbf{n}=\frac{\mathbf{s}-\frac{2}{3} \mathbf{B}}{\tau}
$$

where $\mathbf{s}$ is the stress deviator, $\mathbf{B}$ is the state tensor which accounts for kinematic hardening, and $\tau$ is a scalar measure of the stress difference magnitude

$$
\tau=\sqrt{\frac{3}{2}\left(s-\frac{2}{3} B\right):\left(s-\frac{2}{3} B\right)}
$$

Competing non-linear hardening and thermal recovery mechanisms are captured by the evolution equations for the internal state variable $\mathrm{D}$ and the internal state tensor $\mathbf{B}$. Evolution of the internal state variable $D$ is given by

$$
\dot{\mathrm{D}}=\frac{\mathrm{A}_{1} \gamma}{\left(\mathrm{D}-\mathrm{D}_{\mathrm{o}}\right)^{\mathrm{A}_{3}}}-\mathrm{A}_{2}\left(\mathrm{D}-\mathrm{D}_{\mathrm{o}}\right)^{2}
$$

where $D_{0}, A_{1}, A_{2}$, and $A_{3}$ are material parameters. Evolution of the second-order state tensor $\mathbf{B}$ is given by

$$
\dot{B}=\frac{A_{4} d^{\text {in }}}{b^{A_{6}}}-A_{5} b B
$$

where $A_{4}, A_{5}$, and $A_{6}$ are material parameters and $b$ is the magnitude of $B$ as follows

$$
b=\sqrt{\frac{2}{3} \mathbf{B}: \mathbf{B}}
$$


Like existing theories, the new theory uses a hyperbolic sine function in its kinetic equation for the inelastic strain rate to capture both power law secondary creep and power-law breakdown. Also, both the existing and the new theories have an internal state variable which accounts for isotropic hardening and recovery, and an internal state tensor which accounts for kinematic hardening and recovery. However, there are some significant differences between the new theory and the existing viscoplastic theories.

In their evolution equations for the state variables, the previous viscoplastic theories described competing mechanisms of linear hardening, and nonlinear static recovery (Equations 7, 8, and 19) or competing mechanisms of linear hardening, dynamic recovery, and static recovery (Equations 12 and 13). A close examination of the experimental uniaxial compression data for CusilABA revealed that these experiments could be more accurately simulated by using evolutions equations for the state variables which described competing mechanisms of power law hardening and static recovery. Thus, the evolution Equations 23 and 24 were used in the new viscoplastic theory for braze alloys. With these new equations, the combined effects of linear hardening and dynamic recovery (mechanisms which depend on the inelastic rate) are being described by a single power law hardening term. The only justification for using the power law hardening term is that it simply provided a better fit to the experimental braze data.

A variety of deformation mechanisms are activated at different temperatures during a brazing process. Each of these deformation mechanisms will be associated with different activation energies and different values for material parameter p. Miller (1976) and Freed and Walker (1993) account for changes in activation energy by modifying their Arrhenius function of temperature $f$ with an extra temperature-dependent term (Equation 6). In the new viscoplastic theory, variations in the controlling deformation mechanism are accounted for by simply allowing $f$ and $p$ to be user prescribed functions of temperature.

Finally, in the new theory the state variable $\mathrm{D}$ is scaled by a function of the absolute temperature, $\alpha(\theta)$, in the kinetic equation for the inelastic strain rate, Equation 20. The introduction of this scalar function allows us to vary with temperature the effects of change in the isotropic state on the inelastic rate.

The new viscoplastic theory was implemented in the finite element codes JAC2D (Biffle and Blanford, 1994), and JAS3D (Blanford, 1995). Material parameter names used in these implementations are described in Appendix A. The state of the material is defined by the state scalar D and state tensor $\mathbf{B}$. In the current implementation, the model assumes that the material is initially fully recovered and state tensor $\mathbf{B}$ is initially equal to the null tensor, and state scalar $\mathrm{D}$ is initialized to a value equal to 1.001 times $\mathrm{D}_{\mathrm{o}}$ to prevent division by zero in Equation 23 . 


\section{Numerical Integration of the New Theory}

The Power-Law Secondary Creep theory in JAC2D (Stone and Morgan, 1989) is currently integrated using a forward Euler algorithm with adaptive time step size selection which was originally developed by Zienkiewicz and Cormeau (1974). Zienkiewicz and Cormeau decided to use an inexpensive forward Euler algorithm because the step size is often limited by stability constraints and not accuracy. Since the forward Euler algorithm with adaptive time step size selection works well for the power law creep theory, we decided to initially use this same simple algorithm for the new viscoplastic theory. For this algorithm to remain stable with the new viscoplastic theory, the time step, $\Delta t$, must be chosen such that

$$
\Delta \mathrm{t} \leq \frac{2 \alpha \mathrm{D}}{3 \mathrm{Gfp} \sinh ^{\mathrm{p}-1}\left(\frac{\tau}{\alpha \mathrm{D}}\right) \cosh \left(\frac{\tau}{\alpha \mathrm{D}}\right)}
$$

where $G$ is the shear modulus, $f, p$, and $\alpha$ are material parameters used in the kinetic equation for the inelastic strain rate, Equation $20, \tau$ is a measure of the stress difference as given by Equation 22, and $\mathrm{D}$ is the internal state variable. The following additional checks are also made to ensure that the step size is small enough to accurately integrate the evolution equations for the state variable $\mathrm{D}$ and the state tensor $\mathbf{B}$

$$
\Delta t \leq \sqrt{\frac{2 \delta \mathrm{D}_{\mathrm{o}} \Delta \mathrm{t}_{\mathrm{p}}}{\left|\dot{\mathrm{D}}_{2}-\dot{\mathrm{D}}_{1}\right|}}
$$

and

$$
\Delta \mathrm{t} \leq \sqrt{\frac{2 \delta \mathrm{D}_{\mathrm{o}} \Delta \mathrm{t}_{\mathrm{p}}}{\left|\dot{\mathrm{b}}_{2}-\dot{\mathrm{b}}_{1}\right|}}
$$

where $\delta$ is a measure of the allowable error and in the current implementation is given a value of $1.0 \times 10^{-3}, D_{o}$ is the reference value for the internal state variable $D, \Delta t_{p}$ is the size of the previous step, $\dot{D}_{2}$ is the time rate of change of the state variable at the end of the previous step, and $\dot{D}_{1}$ is the time rate of change of the state variable at the beginning of the previous step, $\vec{b}_{2}$ is the time rate of change of the magnitude of the state tensor $\mathbf{B}$ at the end of the previous step, and $\dot{b_{1}}$ is the time rate of change of the magnitude of the state tensor $\mathbf{B}$ at the beginning of the previous step. Notice that the critical time step size is inversely related to the change in the state variable rates. In other words, Equations 27 and 28 ensure the accuracy of the forward Euler integration by limiting the allowable change in the state variable rates to a very small value. During most of the finite element simulations, the smallest critical time step is given by the stability criterion, Equation 26 . The full development of Equations 26 through 28 is given in Appendix B. Alternate integration algorithms which may be more efficient than the forward Euler algorithm are currently being investigated. 


\section{Selection of Viscoplastic Material Parameters for CusilABA}

The selection of material parameters for viscoplastic theories can be very difficult because the state of the material cannot be directly measured and it is often changing during even the simplest uniaxial and creep compression experiments. In this chapter, two different processes for selecting material parameters for the new viscoplastic theory are presented. The first process is entirely manual and the second process is automated and uses the Levenberg Marquardt Nonlinear Least Squares Algorithm (More, 1978).

Material parameters for the new viscoplastic theory were initially obtained using the following manual process. Standard uniaxial compression and creep compression experiments were performed by Stephens et al. (1993). A minimum creep rate versus stress plot was then generated from the experimental data (Figure 4). From the minimum creep rate plot, the stress level associated with the initiation of power-law breakdown was estimated to be approximately $50 \mathrm{MPa}$ (Figure 6). This stress level was used as the initial estimate for material parameter $D_{0}$.

Young's modulus and Poisson's ratio for a $67 \mathrm{Ag}-33 \mathrm{Cu}$ braze alloy were obtained by Gieske (1990) from longitudinal and shear stress wave velocity measurements. Since, CusilABA has a composition very similar to the $67 \mathrm{Ag}-33 \mathrm{Cu}$ alloy, it is also expected to have very similar elastic properties. Thus, the elastic properties measured by Gieske were used as estimates for the elastic properties of CusilABA. Young's modulus for CusilABA could also be estimated by measuring the initial slope of the stress-strain curve generated during the uniaxial compression experiments. However, the slope of this curve is very sensitive to the stiffness of the load frame/fixture system and often does not provide a good estimate for Young's modulus.

The next step was to obtain values for material parameters $f$ and $p$ which define the inelastic strain rate associated with a given stress level and internal state. This step is difficult because the internal state of the material cannot be directly measured and the internal state variables, D and $\mathbf{B}$, change during many of the creep compression and uniaxial compression experiments. For example, during the $250^{\circ} \mathrm{C}$ uniaxial compression test (Figure 1), the material exhibits a significant amount of strain-hardening which means that the state of the material is changing during this experiment. Also, during the $250^{\circ} \mathrm{C}$ and $350^{\circ} \mathrm{C}$ creep compression experiments the material exhibits an initial inelastic strain (creep) rate that is significantly higher than the steady state creep rate; thus, the state of the material is also changing significantly during these experiments and causing the creep rate to decrease.

During the creep compression experiments, the steady state or minimum creep rate is recorded along with the corresponding true stress and inelastic strain. If we assume that the recovery is negligible during these constant temperature experiments, $A_{2}=0$, then Equation 23 indicates that the current state, $D$, is only a function of the initial state and the inelastic strain. Results from the uniaxial compression tests are used to generate current state, D, estimates from inelastic strain measurements with the following process. If we assume that: (1) $\alpha$ is equal to 1.0 , (2) changes in state are purely isotropic, i.e. $B=0,(3) \mathrm{D}$ has an initial value equal to $D_{0}$ and (4) the inelastic rate, $\gamma$, is constant during the uniaxial compression experiments when the 
braze is strain hardening and the material state is changing, then the following estimate for the state of the material, D, during a uniaxial compression experiment can be obtained from Eq. 20

$$
\frac{D}{\sigma}=\frac{D_{0}}{\sigma_{0}}
$$

where $D_{0}$ is the initial value for the internal state variable (50 MPa), $\sigma$ is the current stress, $\sigma_{0}$ is the stress associated with the point at which the material state begins to change and is assumed to be equal to the yield strength of the material. For example, during the $250^{\circ} \mathrm{C}$ uniaxial compression test (Figure 1), the braze exhibits an initial yield strength of $188 \mathrm{MPa}$ and strain hardens to a stress level of $423 \mathrm{MPa}$ at the end of the test when the total true strain is 0.16 and the inelastic strain is approximately 0.155 . The stress level changes by a factor of 2.25 during this test, and Equation 29 indicates that the material state is also expected to change by a factor of 2.25 from $50 \mathrm{MPa}$ to $112.5 \mathrm{MPa}$ during this test. Thus, during a $250^{\circ} \mathrm{C}$ creep compression experiment in which the inelastic strain associated with the steady state creep rate is 0.155 , the example result indicates that the corresponding estimate for the current value of state variable $\mathrm{D}$ is $112.5 \mathrm{MPa}$.

Values for true stress, inelastic strain rate, and corresponding estimated values for the internal state, $\mathrm{D}$, are given in Table 1 . Note that the state of the material, $\mathrm{D}$, is expected to increase significantly more during the low temperature experiments than during the high temperature experiments.

Values for material parameters $\mathrm{p}$ and $\mathrm{f}$ were then obtained by taking the natural log of terms in Equation 20 as follows

$$
\ln (\gamma)=\ln (f)+p \ln \left(\sinh \left(\frac{\tau}{\alpha D}\right)\right)
$$

Data given in Table 1 was then plotted and simple linear regression was used to obtain material parameters $p$ and $f$ (Figure 10). Material parameters $p$ and $f$ are plotted as functions of temperature in Figures 11 and 12 . These plots clearly show a dramatic change in the materials response at the transition temperature which is approximately one-half the liquidus temperature for the braze alloy. Above the transition temperature, material parameter $\mathrm{p}$ has a value near 2 which suggests that the controlling deformation mechanism is grain boundary sliding (Sherby and Burke, 1968), and a simple Arrhenius fit can be used for $\mathrm{f}$. Below the transition temperature, the deformation mechanism is changing to obstacle-controlled dislocation glide (Freed and Walker, 1993), and the value for $\mathrm{p}$ dramatically increases. Since the activation energies associated with different deformation mechanisms are not equal, a single Arrhenius fit for $f$ over the entire temperature range is not appropriate. 
Table 1. Material Data for CusilABA.

\begin{tabular}{|c|c|c|c|c|}
\hline Test Type ${ }^{a}$ & $\begin{array}{c}\text { Temperature } \\
\left({ }^{\circ} \mathrm{C}\right)\end{array}$ & $\begin{array}{c}\text { Inelastic } \\
\text { Strain Rate - } \gamma \\
\left(\mathbf{s}^{-1}\right)\end{array}$ & $\begin{array}{c}\text { True Stress } \\
\text { (MPa) }\end{array}$ & $\begin{array}{c}\mathrm{D} \text { - Estimate } \\
(\mathrm{MPa})\end{array}$ \\
\hline $\mathrm{UC}$ & 20 & $1.12 \times 10^{-4}$ & 217.00 & 50.0 \\
\hline $\mathrm{CC}$ & 250 & $9.57 e-8$ & 310.32 & 100.3 \\
\hline $\mathrm{CC}$ & 250 & $2.98 \mathrm{e}-7$ & 345.13 & 104.3 \\
\hline $\mathrm{CC}$ & 250 & $9.40 \mathrm{e}-7$ & 390.86 & 112.5 \\
\hline UC & 250 & $1.12 \mathrm{e}-4$ & 188.0 & 50.0 \\
\hline $\mathrm{CC}$ & 350 & $2.07 e-7$ & 143.96 & 75.9 \\
\hline $\mathrm{CC}$ & 350 & $7.53 e-7$ & 188.86 & 80.9 \\
\hline $\mathrm{CC}$ & 350 & $2.67 e-6$ & 229.94 & 83.8 \\
\hline $\mathrm{CC}$ & 450 & $1.78 \mathrm{e}-6$ & 59.23 & 66.5 \\
\hline $\mathrm{CC}$ & 450 & $7.60 e-6$ & 103.47 & 66.5 \\
\hline $\mathrm{CC}$ & 450 & $4.79 e-5$ & 155.57 & 66.5 \\
\hline UC & 450 & $1.26 \mathrm{e}-4$ & 150.0 & 50.0 \\
\hline $\mathrm{CC}$ & 550 & $7.17 e-7$ & 7.55 & 52.5 \\
\hline $\mathrm{CC}$ & 550 & $2.01 e-6$ & 12.45 & 52.5 \\
\hline $\mathrm{CC}$ & 550 & $1.35 e-5$ & 29.90 & 52.5 \\
\hline $\mathrm{CC}$ & 550 & $8.94 e-5$ & 60.87 & 52.5 \\
\hline $\mathrm{CC}$ & 650 & $7.56 \mathrm{e}-7$ & 1.51 & 50.0 \\
\hline $\mathrm{CC}$ & 650 & $1.83 e-6$ & 2.88 & 50.0 \\
\hline $\mathrm{CC}$ & 650 & $5.59 e-5$ & 14.51 & 50.0 \\
\hline $\mathrm{UC}$ & 650 & $1.65 e-4$ & 22.8 & 50.0 \\
\hline $\mathrm{CC}$ & 748 & $1.21 \mathrm{e}-5$ & 1.10 & 50.0 \\
\hline $\mathrm{CC}$ & 748 & $1.14 \mathrm{e}-4$ & 4.20 & 50.0 \\
\hline $\mathrm{CC}$ & 748 & $3.31 \mathrm{e}-4$ & 8.53 & 50.0 \\
\hline
\end{tabular}

a. $\mathrm{UC}=$ Uniaxial Compression, $\mathrm{CC}=$ Creep Compression 


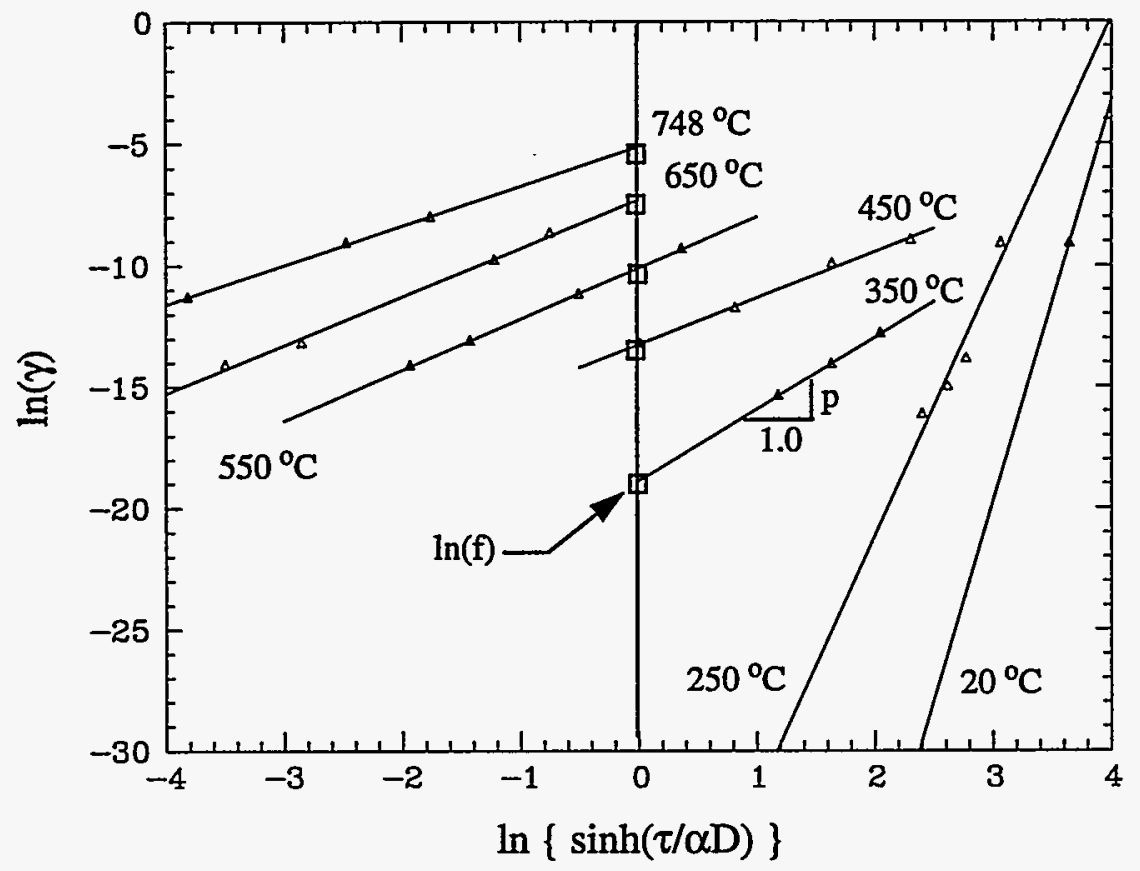

Figure 10. Selection of Material Parameters $\mathrm{p}$ and $\mathrm{f}$ from manual fitting process.

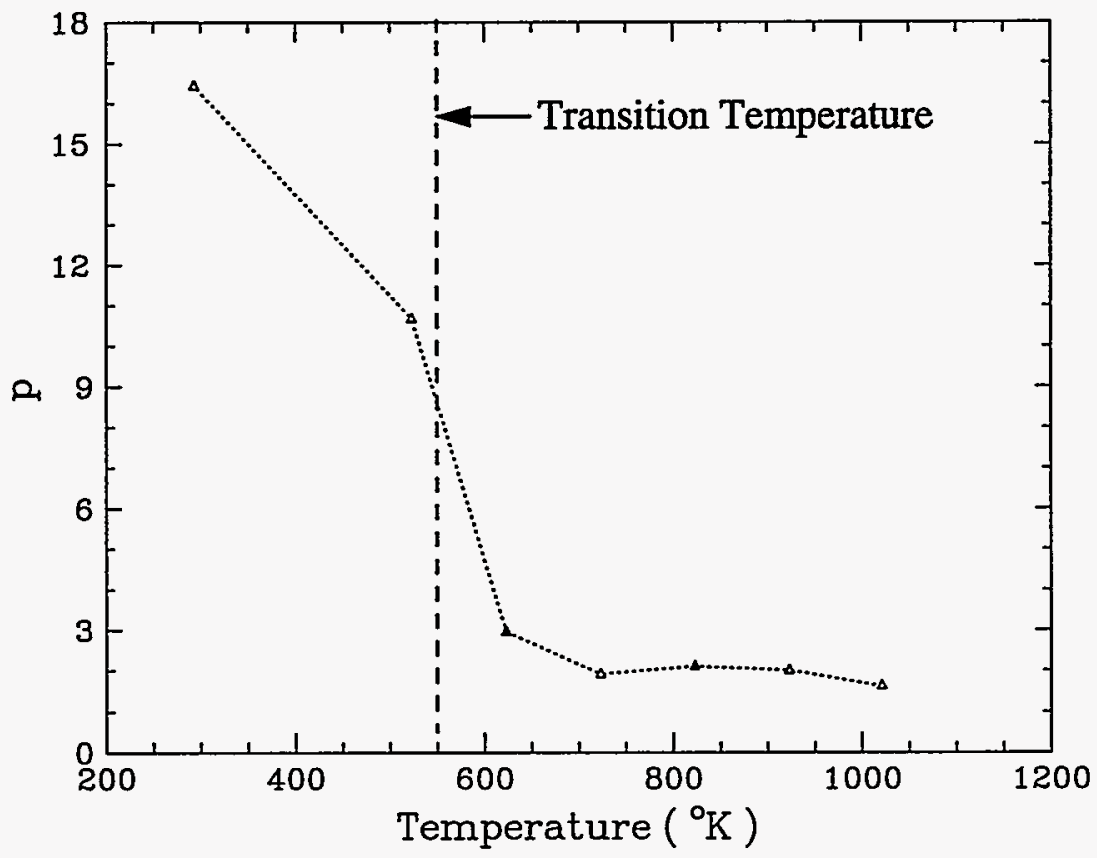

Figure 11. Temperature Dependence of Material Parameter - p.

28 


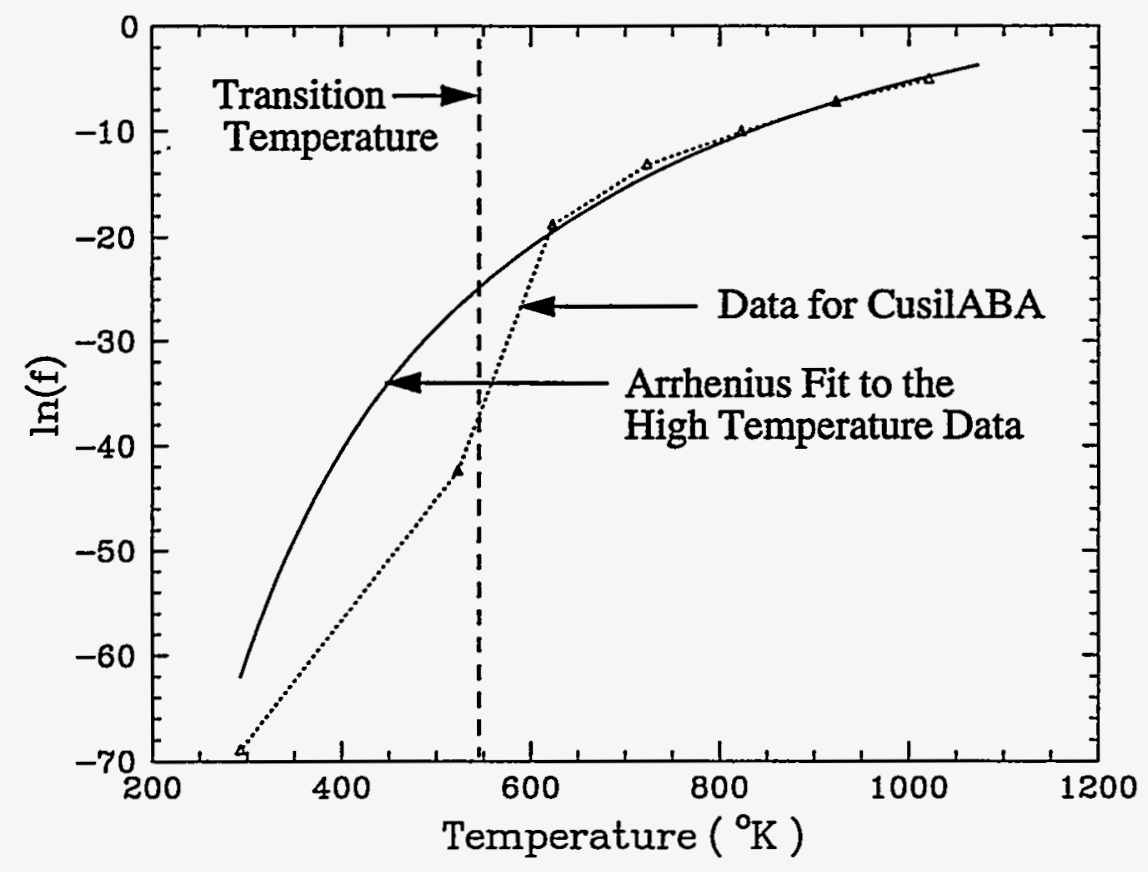

Figure 12. Temperature Dependence of Material Parameter - $f$.

Finally, we need to select the material parameters, $A_{1}$ and $A_{3}$, which govern the evolution of the internal state variable, $D$. If the room temperature stress-strain curve exhibits linear hardening then a hardening exponent, $A_{3}$, near zero should be used. If the stress-strain curves are more rounded in the inelastic regime, then an $A_{3}$ with a value greater than zero should be used (Figure 13). For CusilABA an $A_{3}$ of 1.3 was selected. Values for $A_{1}$ can then be selected to fit the slopes of the stress-strain curves in the inelastic regime. The effect of various selections for $A_{1}$ is shown in Figure 14.

The material parameters obtained using the manual data fitting process are summarized in Table 2. This table shows that, as expected, many of the material parameters are temperature dependent. At this time, we have made no attempt to identify functions of temperature which provide the best fit to the material parameter data. In the numerical simulations, when material is subjected to a temperature that is not listed in Table 2, material parameter estimates are automatically obtained from a simple linear interpolation from the tabulated data. Note that values for the natural log of $f$ are given in Table 2 in place of values for $f$ because for this material parameter, linear interpolation was performed on the tabulated $\ln (f)$ data and $f$ was subsequently computed from the resulting value. This is analogous to fitting the data in Figure 12 with piecewise linear segments. 


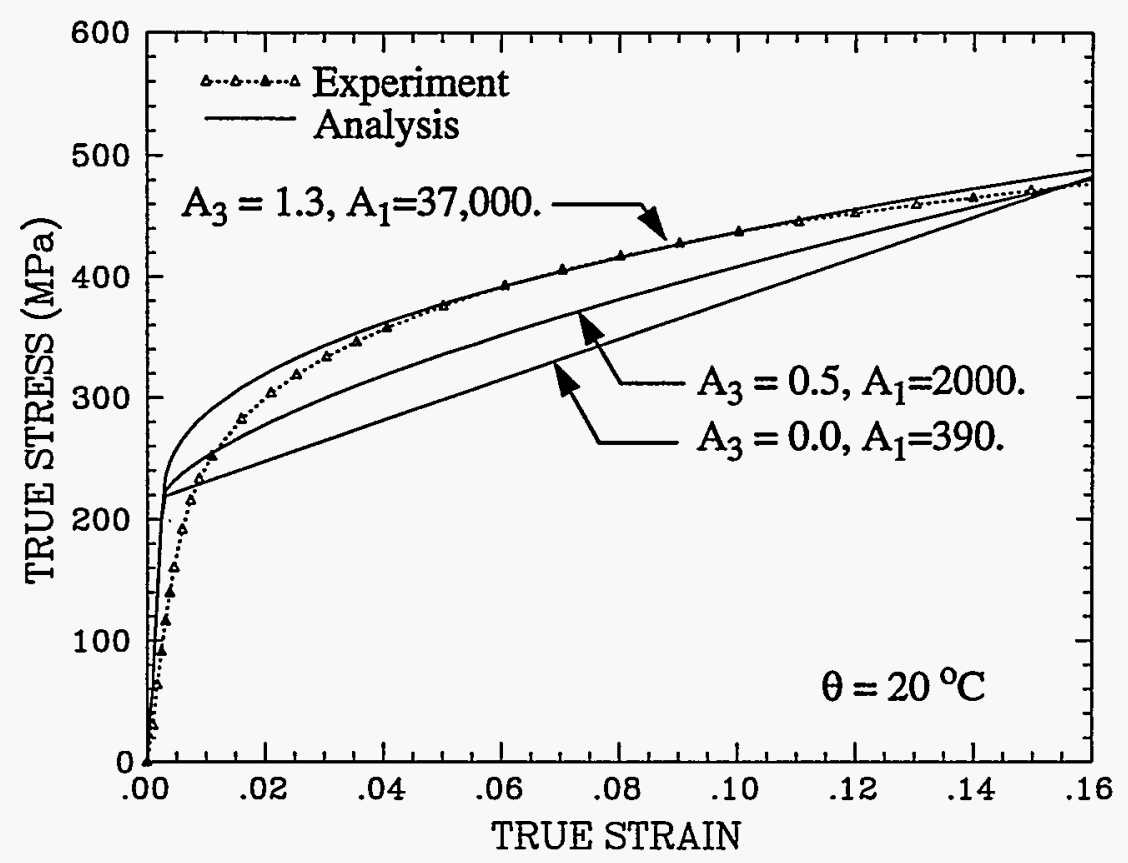

Figure 13. Comparison of Uniaxial Response Predicted Using Various Values for Material Parameters $A_{1}$ and $A_{3}$ With the Experimental Results.

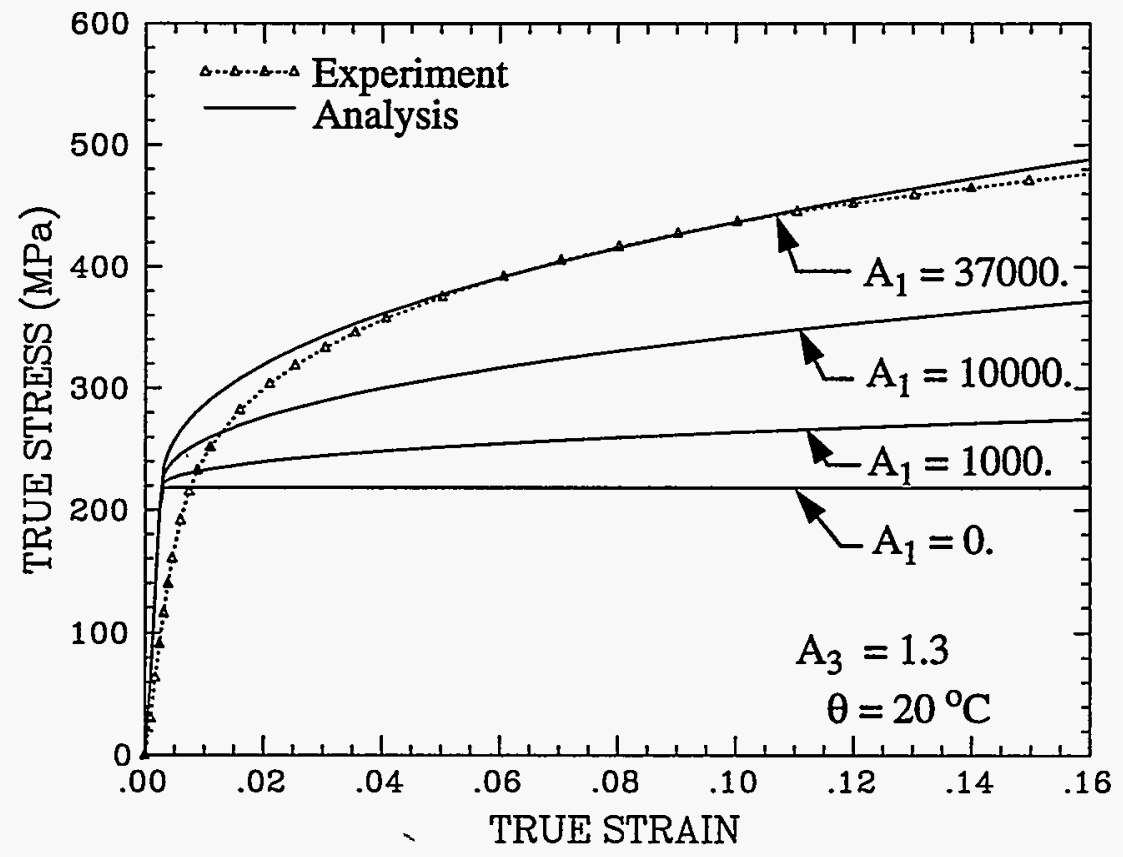

Figure 14. Comparison of Uniaxial Response Predicted Using Various Values for Material Parameter $\mathrm{A}_{1}$ With the Experimental Results. 
Table 2. Material Parameters for CusilABA - Manual Fitting Process

\begin{tabular}{|c|c|c|c|c|c|c|c|}
\hline Temperature $\left({ }^{\circ} \mathrm{C}\right)$ & 20 & 250 & 350 & 450 & 550 & 650 & 748 \\
\hline Elastic Modulus (MPa) & $93.6 \times 10^{3}$ & $83.9 \times 10^{3}$ & $81.0 \times 10^{3}$ & $77.8 \times 10^{3}$ & $73.5 \times 10^{3}$ & $67.4 \times 10^{3}$ & $59.1 \times 10^{3}$ \\
\hline Poisson's Ratio & 0.363 & 0.371 & 0.373 & 0.375 & 0.381 & 0.389 & 0.402 \\
\hline Flow Rate $-\ln (f)^{a}$ & -69.00 & -42.50 & -18.89 & -13.26 & -10.11 & -7.30 & -5.12 \\
\hline Sinh Exponent - $p$ & 16.43 & 10.67 & 2.952 & 1.906 & 2.098 & 1.994 & 1.620 \\
\hline $\begin{array}{l}\text { Isotropic Hardening - } \mathrm{A}_{1} \\
\qquad\left(\mathrm{MPa}^{\mathrm{A3+1}}\right)\end{array}$ & $37.0 \times 10^{3}$ & $37.0 \times 10^{3}$ & $25.0 \times 10^{3}$ & 600.0 & 300.0 & 0.0 & 0.0 \\
\hline $\begin{array}{c}\text { Isotropic Recovery - } \mathrm{A}_{2} \\
1 /(\mathrm{MPa} \text { sec })\end{array}$ & 0.0 & 0.0 & 0.0 & 0.0 & 0.0 & 0.0 & 0.0 \\
\hline Isotropic Exponent - $\mathrm{A}_{3}$ & \multicolumn{7}{|l|}{1.30} \\
\hline $\begin{array}{c}\text { Kinematic Hardening - } \mathrm{A}_{4} \\
(\mathrm{MPa})^{\mathrm{A} 6+1}\end{array}$ & 0.0 & 0.0 & 0.0 & 0.0 & 0.0 & 0.0 & 0.0 \\
\hline $\begin{array}{c}\text { Kinematic Recovery }-A_{5} \\
1 /(M P a ~ s e c)\end{array}$ & 0.0 & 0.0 & 0.0 & 0.0 & 0.0 & 0.0 & 0.0 \\
\hline Kinematic Exponent - $\mathrm{A}_{6}$ & \multicolumn{7}{|l|}{0.0} \\
\hline Flow Stress - $\mathrm{D}_{\mathrm{o}}(\mathrm{MPa})$ & \multicolumn{7}{|l|}{50.0} \\
\hline
\end{tabular}

a. $f$ has units of $\left(\mathrm{s}^{-1}\right)$.

Other researchers have used a variety optimization tools to obtain material parameters for complex viscoplastic material models (Senseny and Fossum; 1995; Lathrop, 1994). The next step in this investigation was to determine if the fit to the experimental CusilABA data could be improved by using an automated process which minimized the error in a least squares sense. The nonlinear least squares fit to the experimental data was obtained using the Levenberg and Marquardt Nonlinear Least Squares Algorithm (More, 1978) which was coupled to a driver subroutine that exercised the constitutive model and generated uniaxial compression and creep compression response predictions for any prescribed set of material parameters. Material parameters obtained from the manual fitting process were used as initial estimates for the automated fitting process. During the automated fitting process, the elastic parameters were not allowed to vary. Two different sets of material parameters which generated nearly identical fits to the creep compression and uniaxial compression data are shown in Tables 3 and 4. The parameters in Table 3 indicate that the hardening and recovery is purely isotropic and the parameters in Table 4 indicate that the hardening and recovery is purely kinematic. Thus, these results indicate that it is not possible to obtain a unique set of material parameters from the experimental data that is currently available. Additional experiments will be needed to determine how much of the hardening and recovery is isotropic and how much is kinematic. 
Table 3. Material Parameters for CusilABA - Isotropic Hardening / Recovery

\begin{tabular}{|c|c|c|c|c|c|c|c|}
\hline Temperature $\left({ }^{\circ} \mathrm{C}\right)$ & 20 & 250 & 350 & 450 & 550 & 650 & 748 \\
\hline Elastic Modulus (MPa). & $93.6 \times 10^{3}$ & $83.9 \times 10^{3}$ & $81.0 \times 10^{3}$ & $77.8 \times 10^{3}$ & $73.5 \times 10^{3}$ & $67.4 \times 10^{3}$ & $59.1 \times 10^{3}$ \\
\hline Poisson's Ratio & 0.363 & 0.371 & 0.373 & 0.375 & 0.381 & 0.389 & 0.402 \\
\hline Flow Rate $-\ln (f)$ & -59.89 & -56.61 & -20.23 & -13.88 & -10.32 & -7.65 & -5.79 \\
\hline Sinh Exponent - p & 24.00 & 22.50 & 5.303 & 2.589 & 1.941 & 1.691 & 1.256 \\
\hline $\begin{array}{l}\text { Iso. Hardening - } \mathrm{A}_{1} \\
\left(\mathrm{MPa}^{\mathrm{A}+1}\right)\end{array}$ & $1.25 \times 10^{6}$ & $8.19 \times 10^{5}$ & $5.00 \times 10^{5}$ & $3.00 \times 10^{4}$ & 89.1 & 22.5 & 0.0 \\
\hline $\begin{array}{c}\text { Iso. Recovery - } \mathrm{A}_{2} \\
1 /(\mathrm{MPa} \mathrm{sec})\end{array}$ & 0.0 & $1.00 \times 10^{-9}$ & $1.22 \times 10^{-7}$ & $2.07 \times 10^{-5}$ & $1.66 \times 10^{-3}$ & $2.87 \times 10^{-3}$ & $5.00 \times 10^{-3}$ \\
\hline Iso. Exponent - $\mathrm{A}_{3}$ & \multicolumn{7}{|l|}{1.746} \\
\hline $\begin{array}{l}\text { Kin. Hardening - } \mathrm{A}_{4} \\
(\mathrm{MPa})^{\mathrm{A} 6+1}\end{array}$ & 0.0 & 0.0 & 0.0 & 0.0 & 0.0 & 0.0 & 0.0 \\
\hline $\begin{array}{c}\text { Kin. Recovery - } \mathrm{A}_{5} \\
1 /(\mathrm{MPa} \text { sec })\end{array}$ & 0.0 & 0.0 & 0.0 & 0.0 & 0.0 & 0.0 & 0.0 \\
\hline Kin. Exponent - $A_{6}$ & \multicolumn{7}{|l|}{0.0} \\
\hline Flow Stress - $\mathrm{D}_{0}(\mathrm{MPa})$ & \multicolumn{7}{|l|}{50.0} \\
\hline
\end{tabular}

Table 4. Material Parameters for CusilABA - Kinematic Hardening / Recovery

\begin{tabular}{|c|c|c|c|c|c|c|c|}
\hline Temperature $\left({ }^{\circ} \mathrm{C}\right)$ & 20 & 250 & 350 & 450 & 550 & 650 & 748 \\
\hline Elastic Modulus (MPa) & $93.6 \times 10^{3}$ & $83.9 \times 10^{3}$ & $81.0 \times 10^{3}$ & $77.8 \times 10^{3}$ & $73.5 \times 10^{3}$ & $67.4 \times 10^{3}$ & $59.1 \times 10^{3}$ \\
\hline Poisson's Ratio & 0.363 & 0.371 & 0.373 & 0.375 & 0.381 & 0.389 & 0.402 \\
\hline Flow Rate - $\ln (f)$ & -59.89 & -56.61 & -20.23 & -13.88 & -10.32 & -7.65 & -5.79 \\
\hline Sinh Exponent - p & 24.00 & 22.50 & 5.303 & 2.589 & 1.941 & 1.691 & 1.256 \\
\hline $\begin{array}{l}\text { Iso. Hardening - } \mathrm{A}_{1} \\
\left(\mathrm{MPa}^{\mathrm{A}+1}\right)\end{array}$ & 0.0 & 0.0 & 0.0 & 0.0 & 0.0 & 0.0 & 0.0 \\
\hline $\begin{array}{c}\text { Iso. Recovery - } A_{2} \\
1 /(\mathrm{MPa} \mathrm{sec})\end{array}$ & 0.0 & 0.0 & 0.0 & 0.0 & 0.0 & 0.0 & 0.0 \\
\hline Iso. Exponent - $\mathrm{A}_{3}$ & \multicolumn{7}{|l|}{0.0} \\
\hline $\begin{array}{l}\text { Kin. Hardening - } \mathrm{A}_{4} \\
(\mathrm{MPa})^{\mathrm{A} 6+1}\end{array}$ & $21.6 \times 10^{6}$ & $12.3 \times 10^{6}$ & $3.78 \times 10^{6}$ & $7.62 \times 10^{5}$ & 100.0 & 50.0 & 0.0 \\
\hline $\begin{array}{c}\text { Kin. Recovery - } \mathrm{A}_{5} \\
1 /(\mathrm{MPa} \text { sec })\end{array}$ & 0.0 & $2.18 \times 10^{-8}$ & $1.57 \times 10^{-7}$ & $6.71 \times 10^{-5}$ & $2.00 \times 10^{-4}$ & $6.00 \times 10^{-4}$ & $1.80 \times 10^{-3}$ \\
\hline Kin. Exponent - $A_{6}$ & \multicolumn{7}{|l|}{1.746} \\
\hline Flow Stress - $\mathrm{D}_{0}(\mathrm{MPa})$ & \multicolumn{7}{|l|}{50.0} \\
\hline
\end{tabular}




\section{Simulation of Material Characterization Tests for CusilABA}

The next step in this investigation was to simulate the material characterization tests using the new viscoplastic constitutive theory which was implemented in JAC2D (Biffle and Blanford, 1994), and JAS3D (Blanford, 1995). These simulations were performed using JAC2D, the material parameters in Tables 2, 3 or 4, and the axisymmetric finite element models shown in Figure 15. The uniaxial compression tests were simulated by subjecting the model shown in Figure 15a to a constant true strain rate of $1.65 \times 10^{-4} \mathrm{~s}^{-1}$ for 976 seconds by simply displacing the top end of the model at a prescribed variable rate. The constant-load, creep compression tests were simulated by ramping the applied pressure on the loading block in Figure $15 \mathrm{~b}$ up to a prescribed value and then holding it constant for a prescribed amount of time. The loading block was needed for this simulation because the applied load was prescribed during the creep compression tests and not the true axial stress in the rod which changes during the experiment and simulation. Axial compressive stress-strain curves generated by the uniaxial compression simulations are shown in Figures 16,17 and 18 for material parameters from Tables 2, 3 and 4 , respectively.

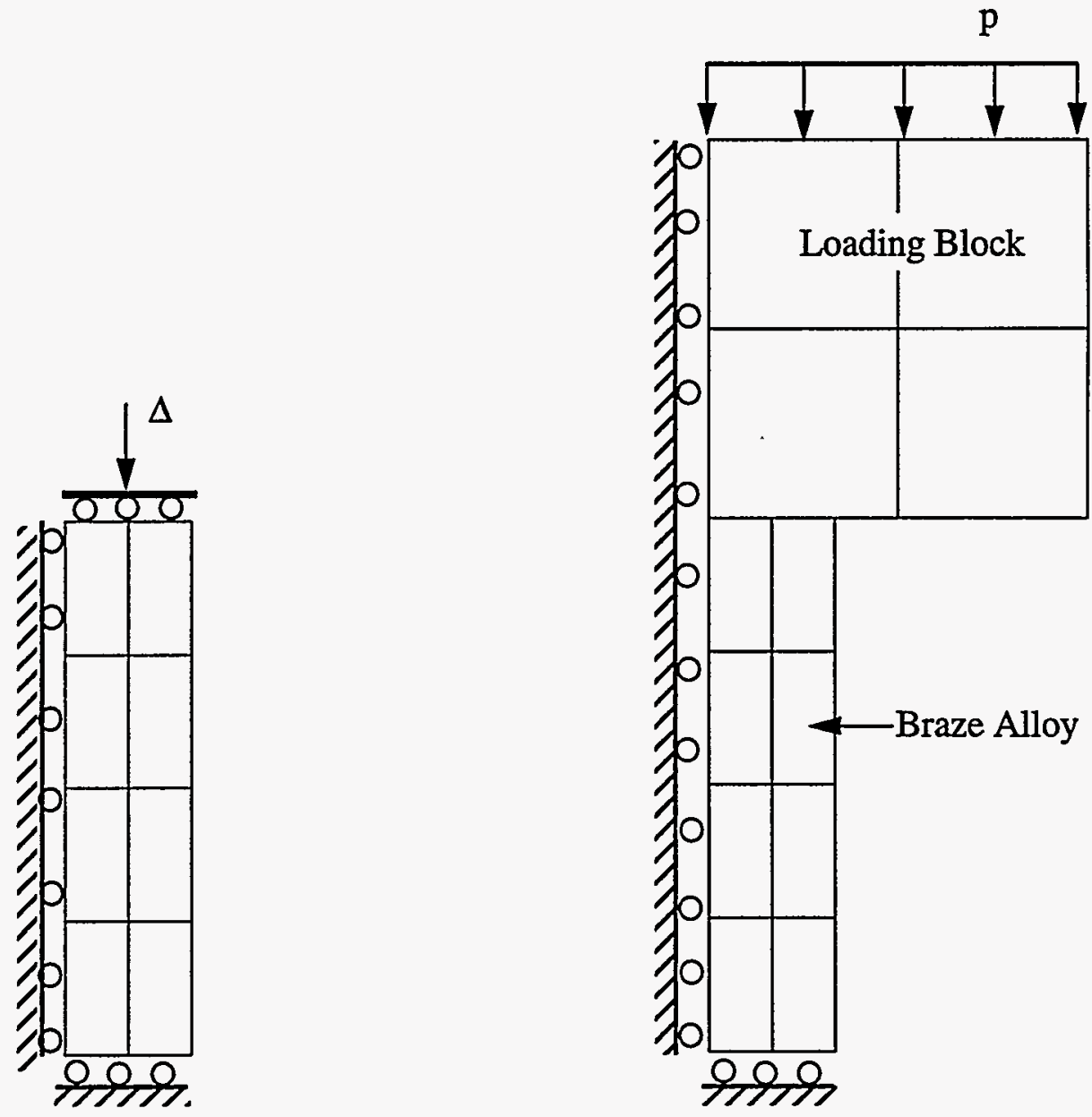

(a.) Uniaxial Compression Test

(b.) Creep Compression Test

Figure 15. Axisymmetric Finite Element Models Used to Simulate the Uniaxial and Creep Compression Experiments. 


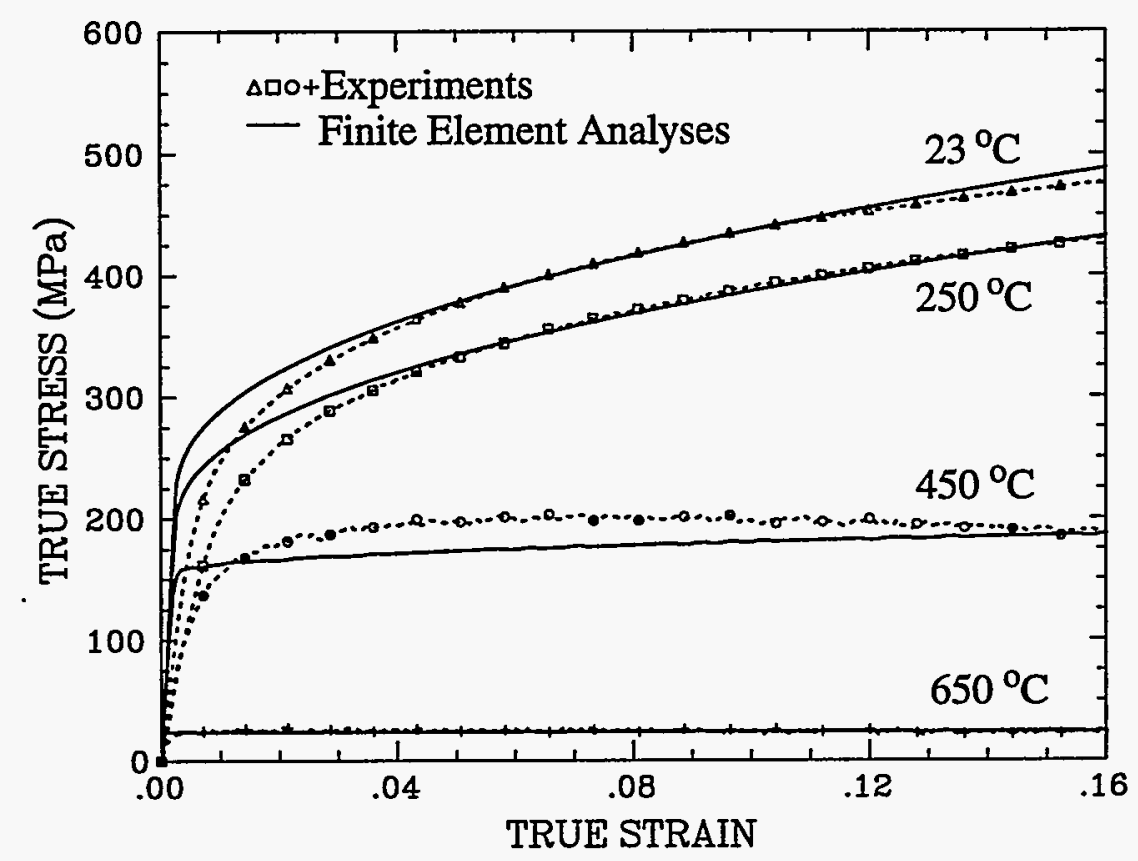

Figure 16. Uniaxial Compression Simulations Compared with Experiments on CusilABA, Material Parameters from Manual Fitting Process - Table 2.

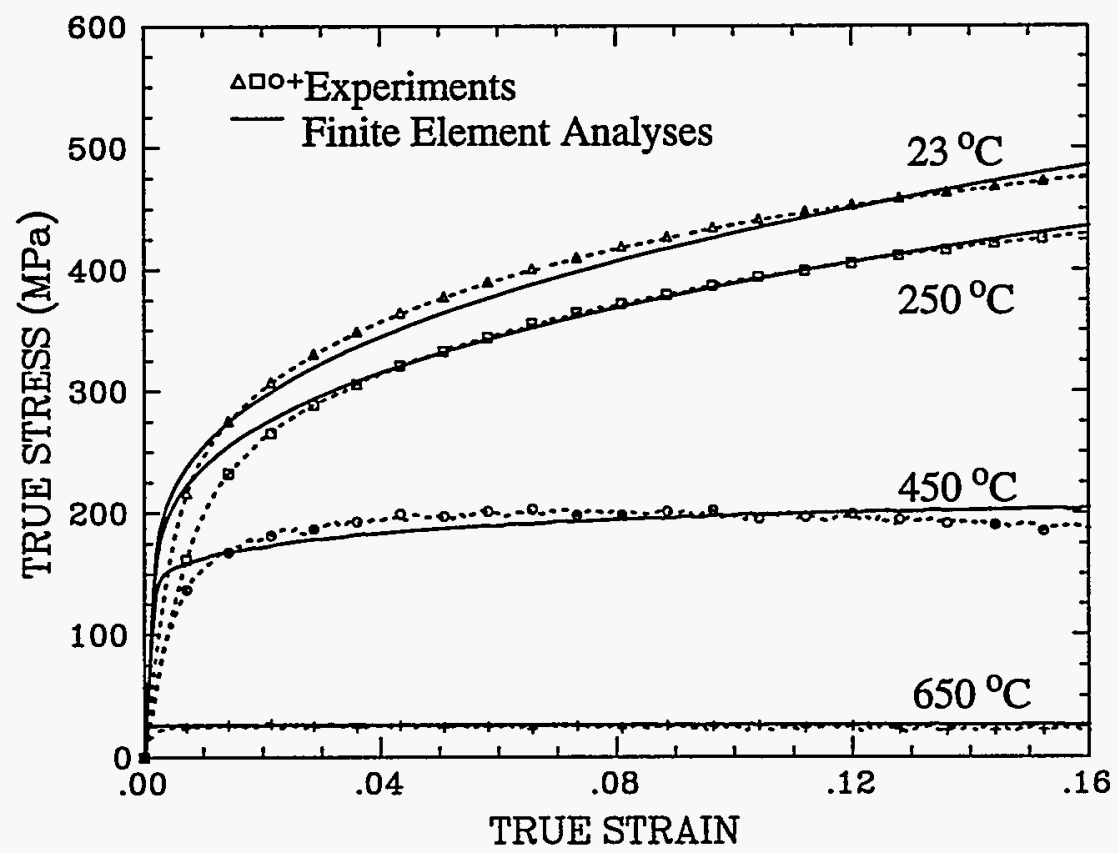

Figure 17. Uniaxial Compression Simulations Compared with Experiments on CusilABA, Simulations Performed Using Isotropic Hardening / Recovery - Table 3. 


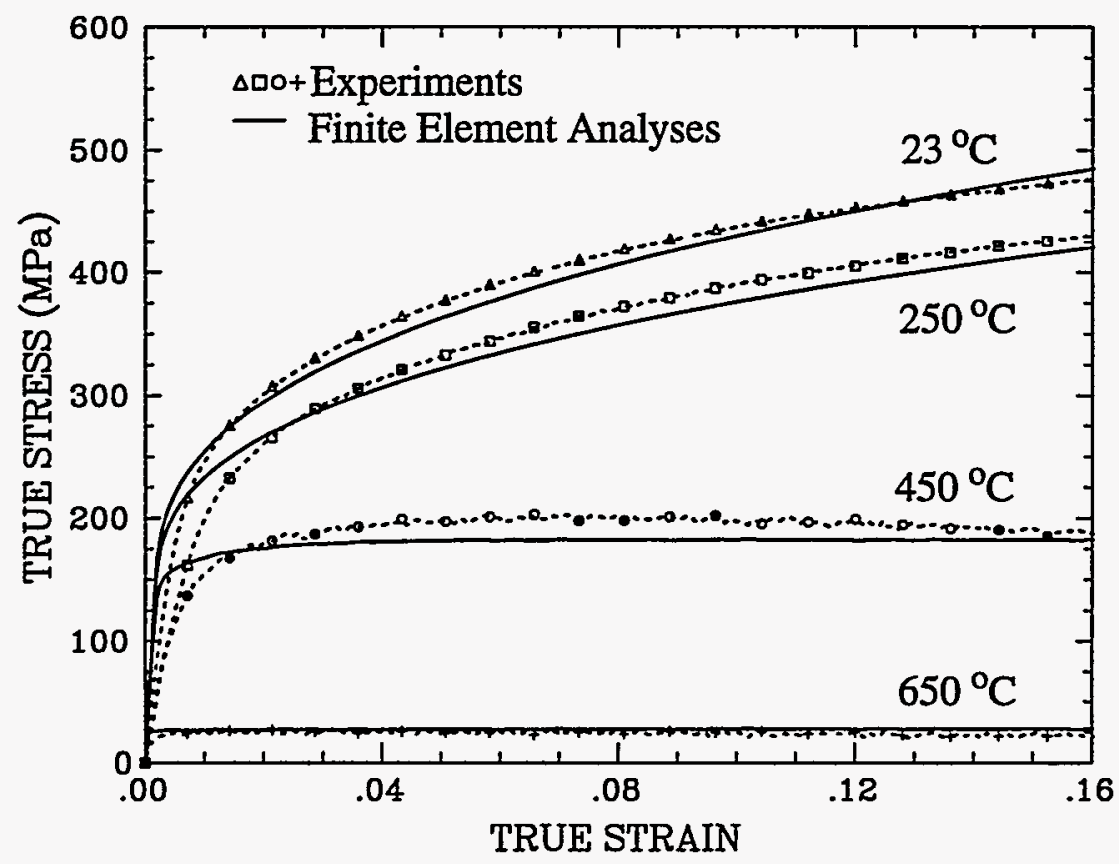

Figure 18. Uniaxial Compression Simulations Compared with Experiments on CusilABA, Simulations Performed Using Kinematic Hardening / Recovery - Table 4.

The results from these simulations match the experimental uniaxial compression test results reasonably well. The fits obtained using the nonlinear least squares process are not significantly better than the fits obtained using the manual process. The automated fits to the experimental data were improved when the elastic parameters were allowed to vary; however, unreasonably low values were then obtained for Young's modulus. This probably occurred because the load frame and/or fixtures used in the uniaxial compression experiments were not stiff enough to generate accurate elastic stress strain data. These results also indicate that the experimental data can be fit by assuming that the hardening and recovery is either entirely isotropic or entirely kinematic. An equally good fit could also be obtained by using a combination of isotropic and kinematic hardening. Thus, it currently will not be possible to obtain a unique set of material parameters which generate a good fit to the existing experimental data.

In the next simulation, the room-temperature uniaxial compression model (Figure 15a) was subjected to uniaxial compression followed by uniaxial tension. Results from this simulation (Figure 19) showed that, as expected, the cyclic response predicted using the isotropic hardening / recovery parameters is significantly different that the response predicted using the kinematic hardening / recovery parameters. Thus, cyclic uniaxial experiments could be used to determine the relative amounts of isotropic and kinematic hardening and recovery. 


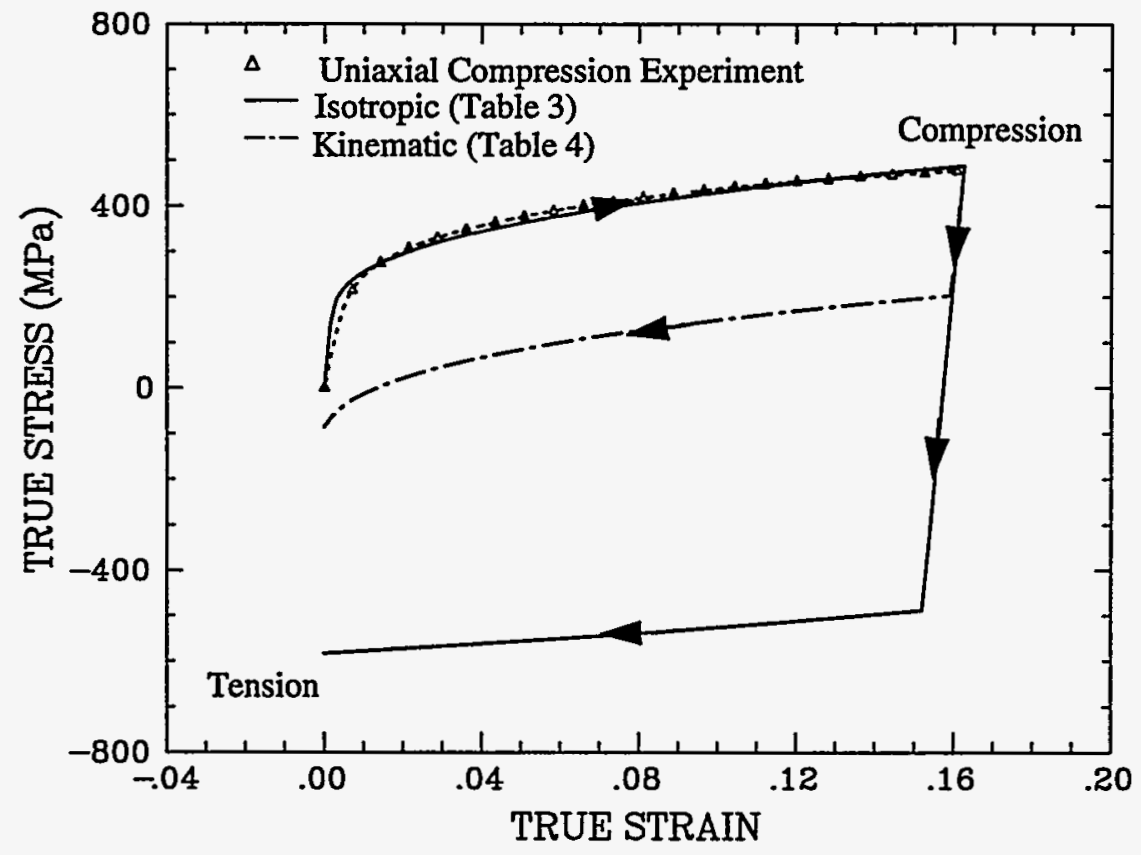

Figure 19. Simulations of a Room-Temperature, Cyclic Uniaxial Test with Material Parameters from Tables 3 and 4.

The final series of material characterization experiments were performed using the creep compression model shown in Figure $15 \mathrm{~b}$ and the isotropic material parameters given in Table 3. During these analyses, the load was ramped to a prescribed value in approximately 18 seconds and then held constant for the duration of the simulation. Results from simulations for a variety of temperatures and applied loads are shown in Figures 20 through 25 . The numbers in these figures represent the engineering stress (applied load divided by the original crosssectional area of the braze alloy specimen). These results show that the model is able to accurately describe the response of the material during the creep compression experiments. Creep compression simulations with the kinematic material parameters given in Table 4 generated very similar results. 


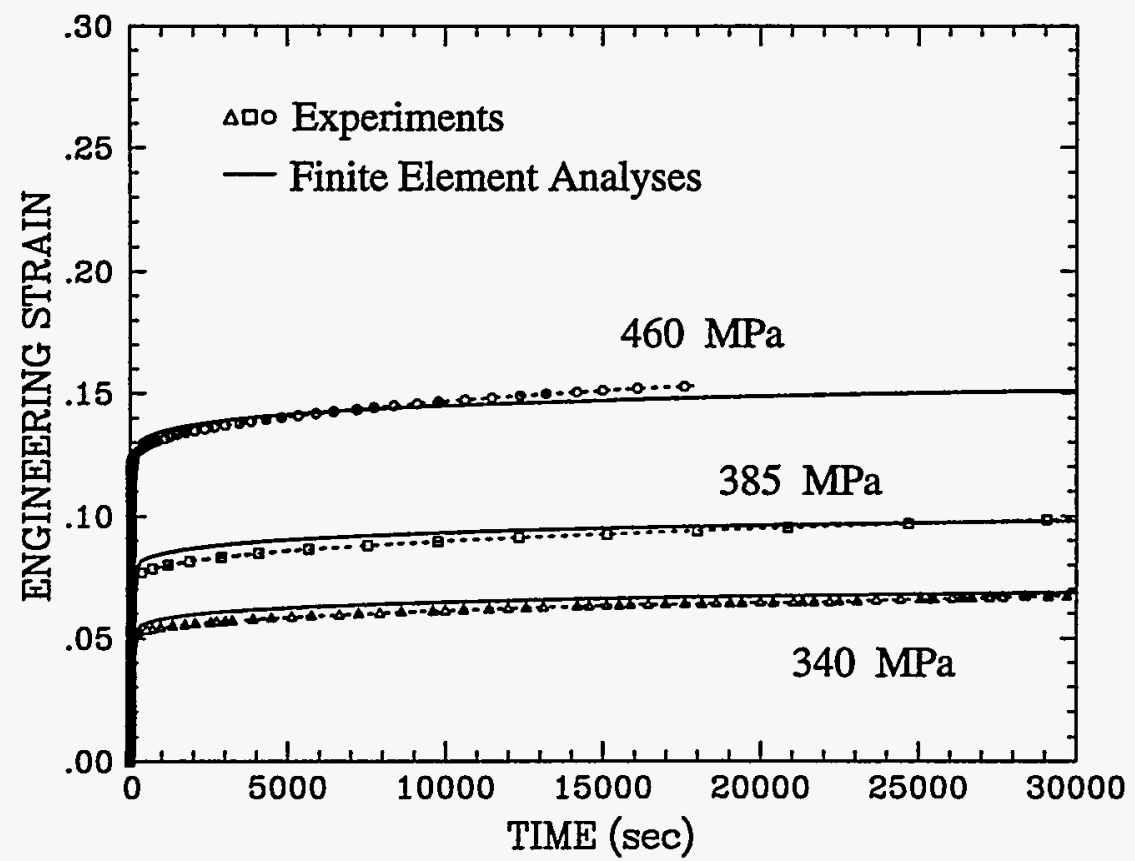

Figure 20. Creep Compression Simulations Compared with Experiments at $250^{\circ} \mathrm{C}$.

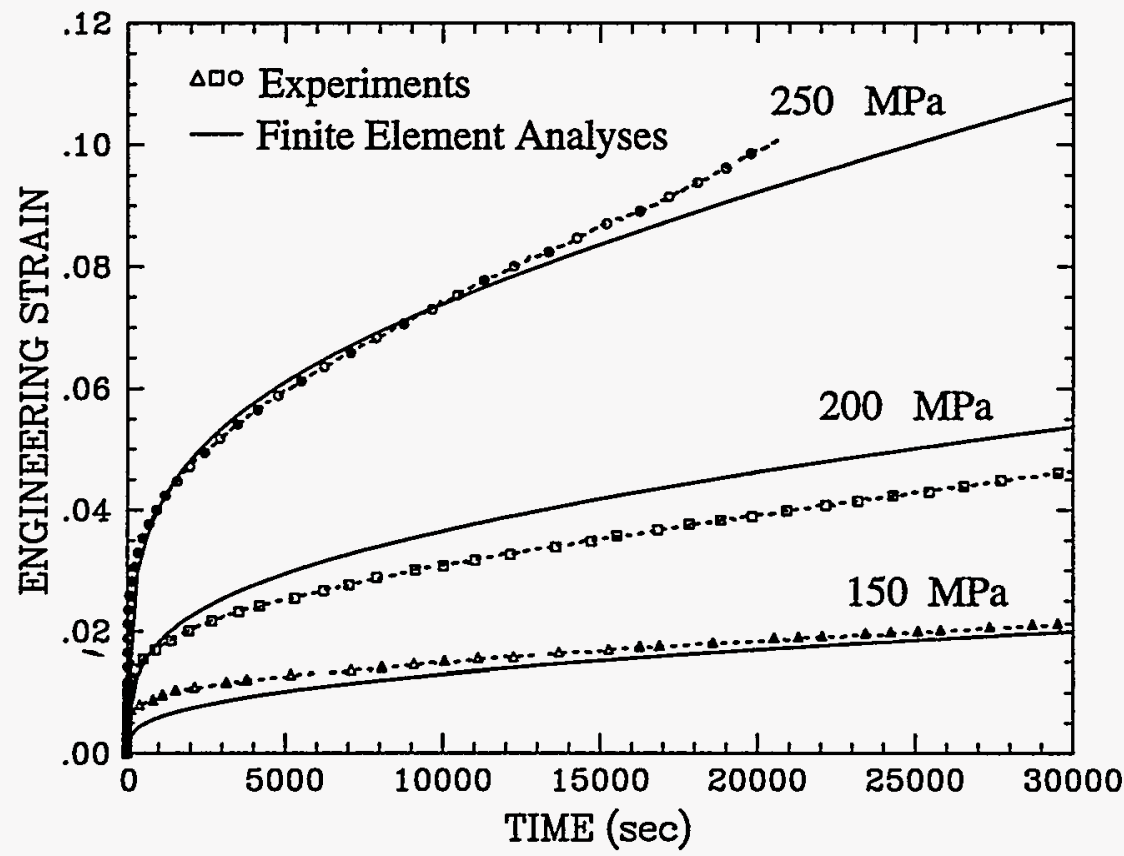

Figure 21. Creep Compression Simulations Compared with Experiments at $350^{\circ} \mathrm{C}$. 


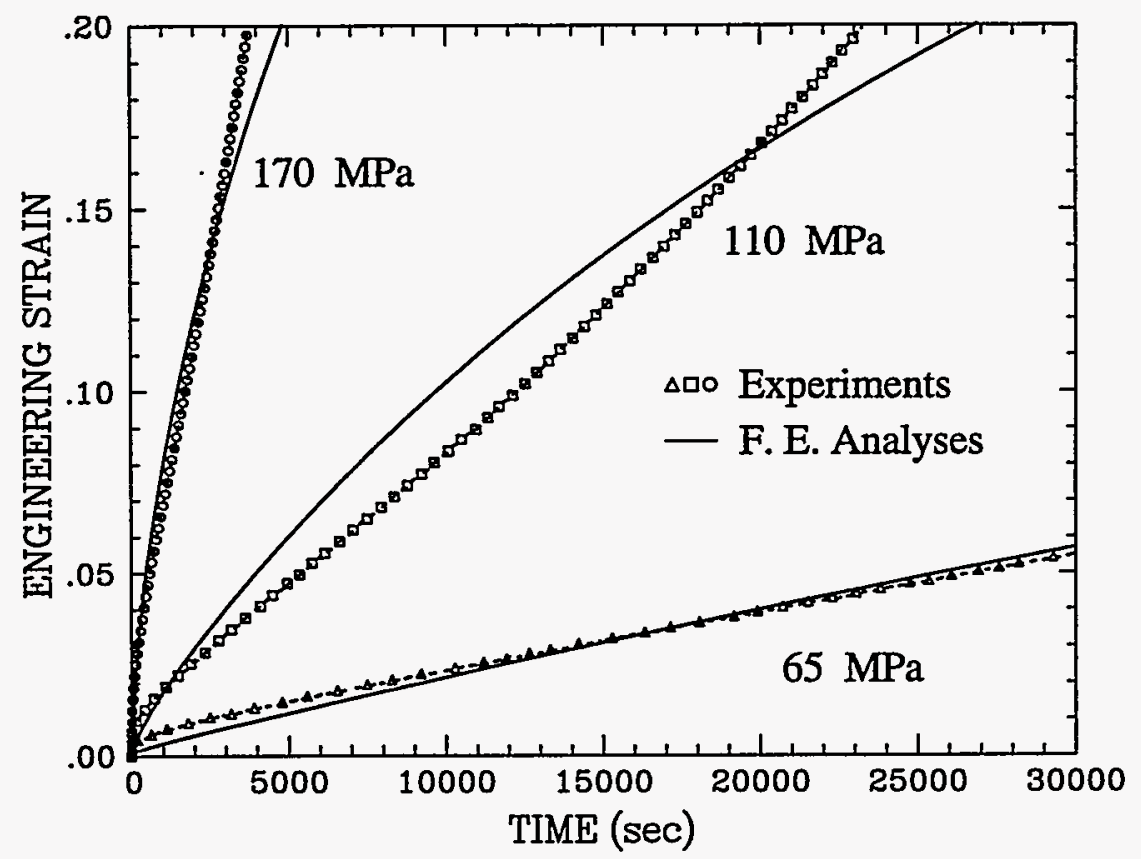

Figure 22. Creep Compression Simulations Compared with Experiments at $450^{\circ} \mathrm{C}$.

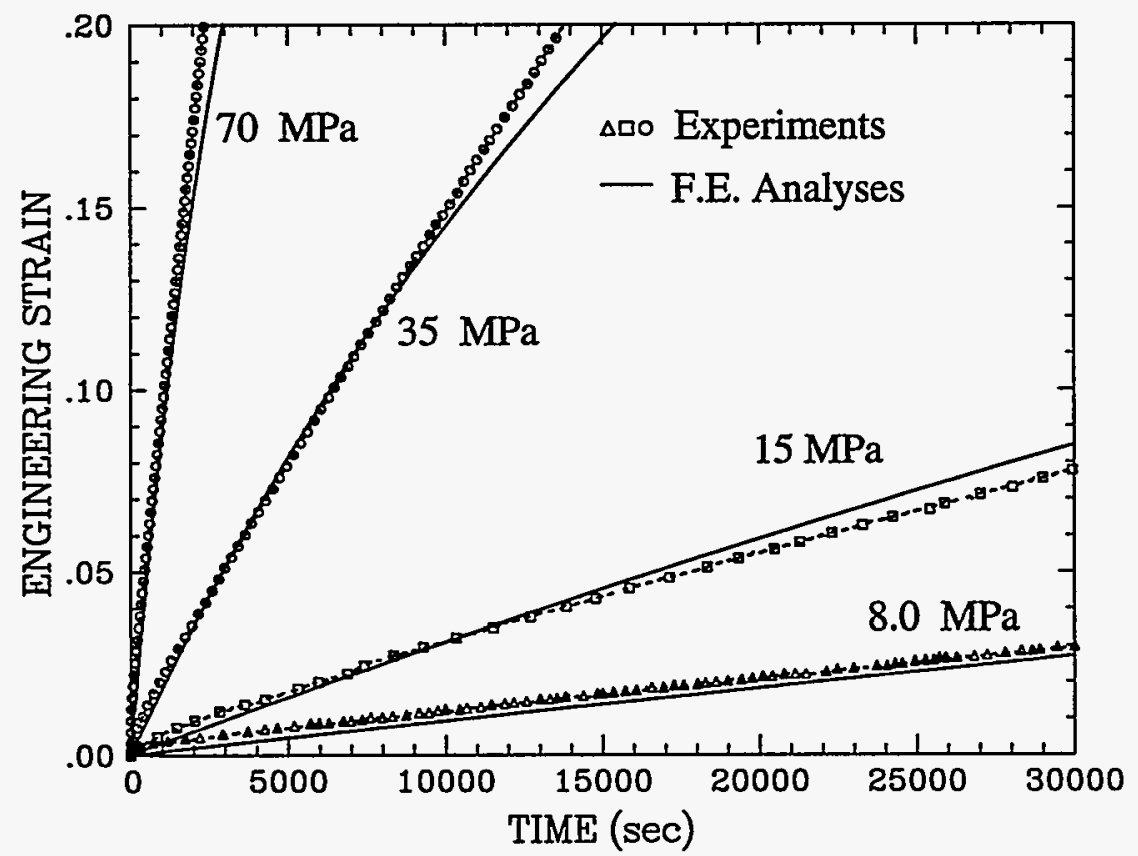

Figure 23. Creep Compression Simulations Compared with Experiments at $550^{\circ} \mathrm{C}$. 


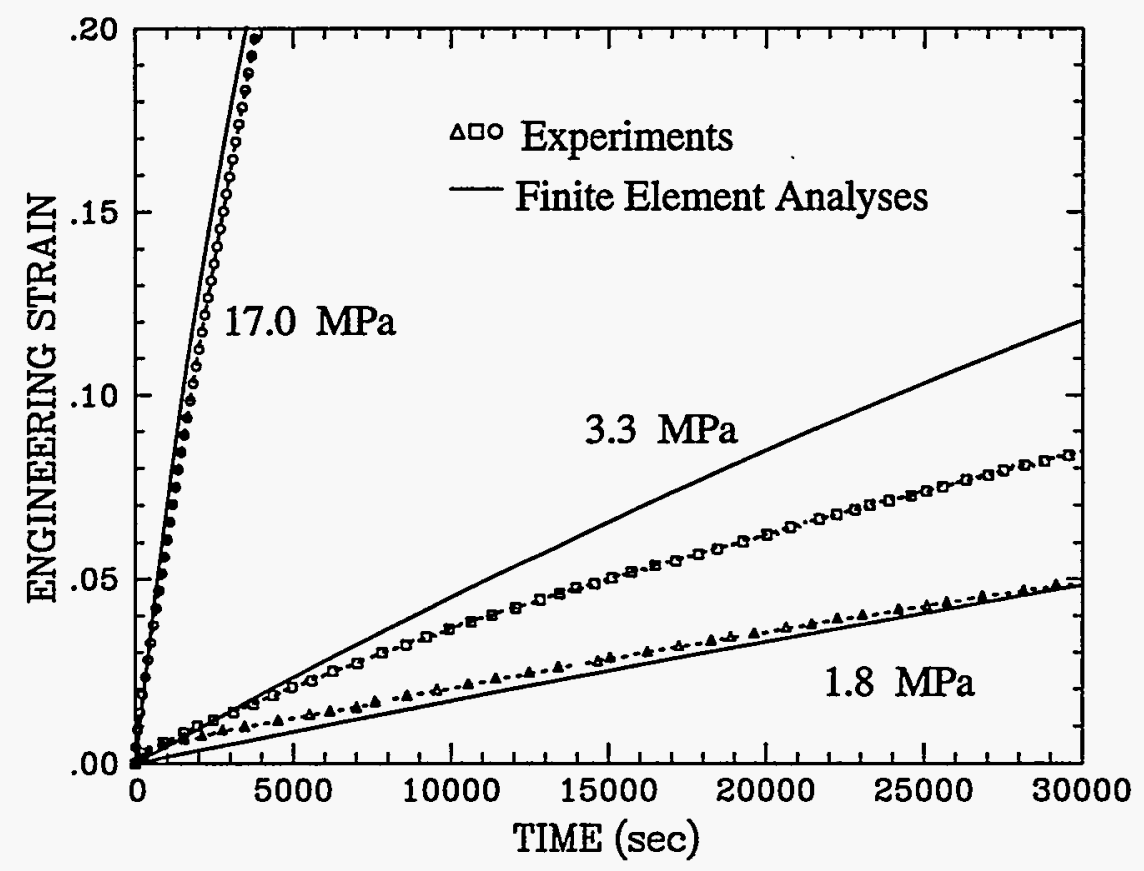

Figure 24. Creep Compression Simulations Compared with Experiments at $650^{\circ} \mathrm{C}$.

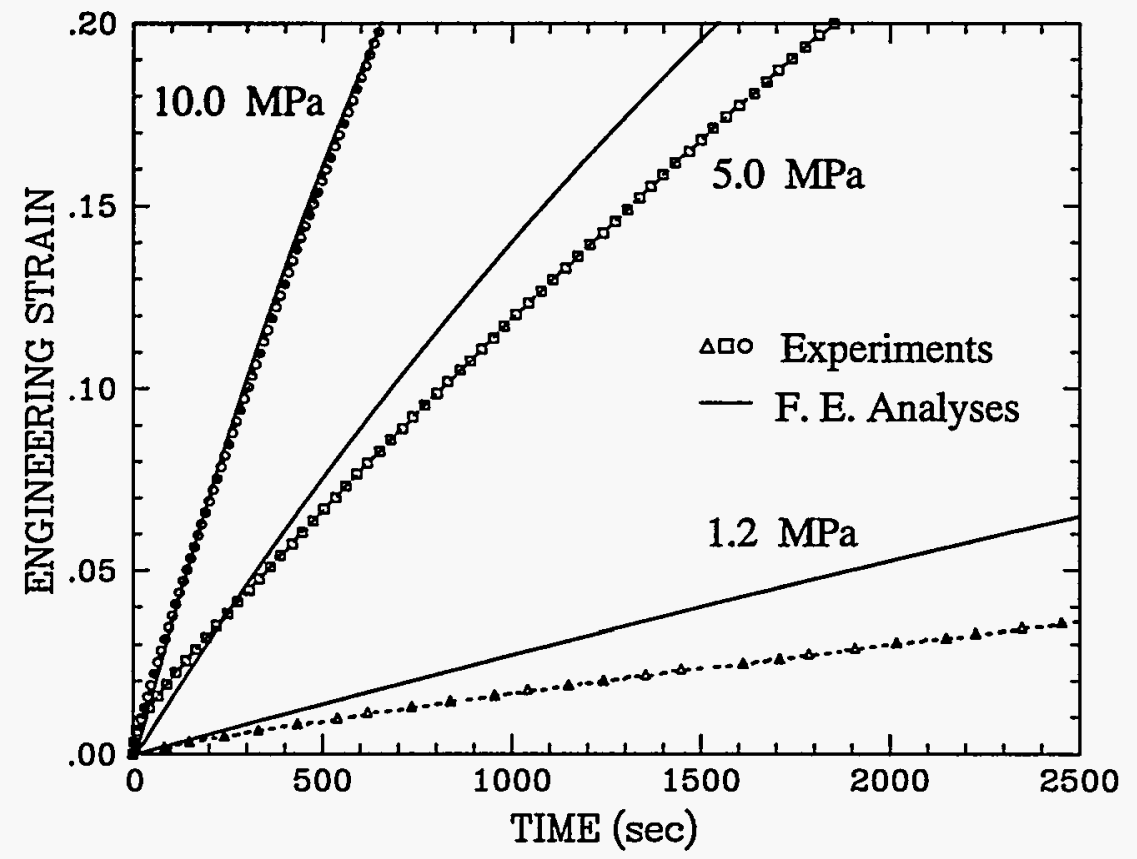

Figure 25. Creep Compression Simulations Compared with Experiments at $748^{\circ} \mathrm{C}$. 


\section{Numerical Simulation of Metal-to-Ceramic Brazing}

Finally, the brazing of an alumina ceramic rod to a Kovar rod was simulated using the finite element model shown in Figure 26. The CusilABA braze layer was modeled using: (1) the new viscoplastic theory, (2) a temperature-dependent vonMises plasticity theory, and (3) a power law secondary creep theory to investigate the effects of braze modeling variations on the residual stress predictions. In all of these simulations, the braze layer is initially uniform and the effects of base metal dissolution into the braze joint on the braze microstructure are not considered. The alumina ceramic and the Kovar were modeled as linear elastic materials. Material parameters used in these simulations are summarized in Tables 2 through 6 . In all of these simulations, the assembly was initially stress free and at the solidus temperature for the braze $\left(780^{\circ} \mathrm{C}\right)$. The model was cooled to room temperature in one hour. The stresses generated by the differential thermal expansion of alumina ceramic and Kovar were investigated. In the first series of simulations, the thermal expansion coefficient for the materials was assumed to remain constant from the solidus temperature down to room temperature (Figure 27). Constant thermal expansion coefficients were used so the effects of braze model variations could be investigated without having the complications caused by using temperature-dependent thermal expansion coefficients.

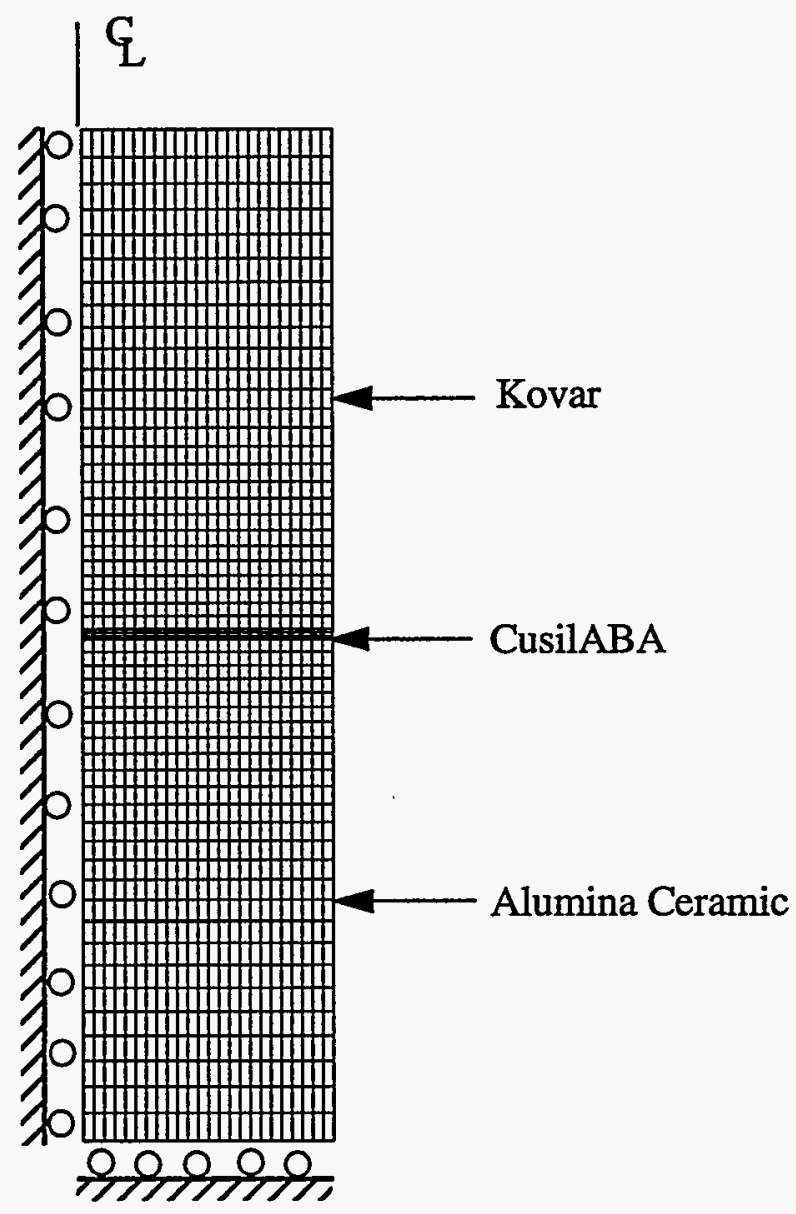

Figure 26. Axisymmetric Finite Element Model of an Alumina Ceramic Rod Brazed to a Kovar Rod with CusilABA. 
Table 5. Material Parameters for CusilABA (vonMises Plasticity and Power Law Creep)

\begin{tabular}{|c|c|c|c|c|c|c|c|}
\hline $\begin{array}{c}\text { Temperature } \\
\left({ }^{\circ} \mathrm{C}\right)\end{array}$ & 20 & 250 & 350 & 450 & 550 & 650 & 748 \\
\hline \hline \multicolumn{7}{|c|}{ CusilABA - von Mises Plasticity } \\
\hline $\begin{array}{c}\text { Elastic Modulus } \\
\text { (MPa) }\end{array}$ & $93.6 \times 10^{3}$ & $83.9 \times 10^{3}$ & $81.0 \times 10^{3}$ & $77.8 \times 10^{3}$ & $73.5 \times 10^{3}$ & $67.4 \times 10^{3}$ & $59.1 \times 10^{3}$ \\
\hline Poisson's Ratio & 0.363 & 0.371 & 0.373 & 0.375 & 0.381 & 0.389 & 0.402 \\
\hline Yield Stress (MPa) & 330.0 & 290.0 & 250.0 & 200.0 & 75.0 & 22.8 & 10.0 \\
\hline $\begin{array}{c}\text { Hard. Modulus } \\
\text { (MPa) }\end{array}$ & 1050.0 & 900.0 & 500.0 & 0.0 & 0.0 & 0.0 & 0.0 \\
\hline \multicolumn{7}{|c|}{ CusilABA - Power Law Creep } \\
\hline $\begin{array}{c}\text { Elastic Modulus } \\
\text { (MPa) }\end{array}$ & $93.6 \times 10^{3}$ & $83.9 \times 10^{3}$ & $81.0 \times 10^{3}$ & $77.8 \times 10^{3}$ & $73.5 \times 10^{3}$ & $67.4 \times 10^{3}$ & $59.1 \times 10^{3}$ \\
\hline Poisson's Ratio & 0.363 & 0.371 & 0.373 & 0.375 & 0.381 & 0.389 & 0.402 \\
\hline Creep Constant & $99.388 \times 10^{3}$ & \\
\hline Stress Exponent & 2.05 & \\
\hline Thermal Constant & $24.308 \times 10^{3}$ &
\end{tabular}

Table 6. Material Parameters for Kovar and Alumina Ceramic

\begin{tabular}{|c|c|c|}
\hline Material & $\begin{array}{c}\text { Elastic } \\
\text { Modulus } \\
(\mathrm{MPa})\end{array}$ & $\begin{array}{c}\text { Poisson's } \\
\text { Ratio }\end{array}$ \\
\hline \hline Kovar & $137.9 \times 10^{3}$ & 0.317 \\
\hline $\begin{array}{c}\text { Alumina } \\
\text { Ceramic }\end{array}$ & $303.4 \times 10^{3}$ & 0.220 \\
\hline
\end{tabular}




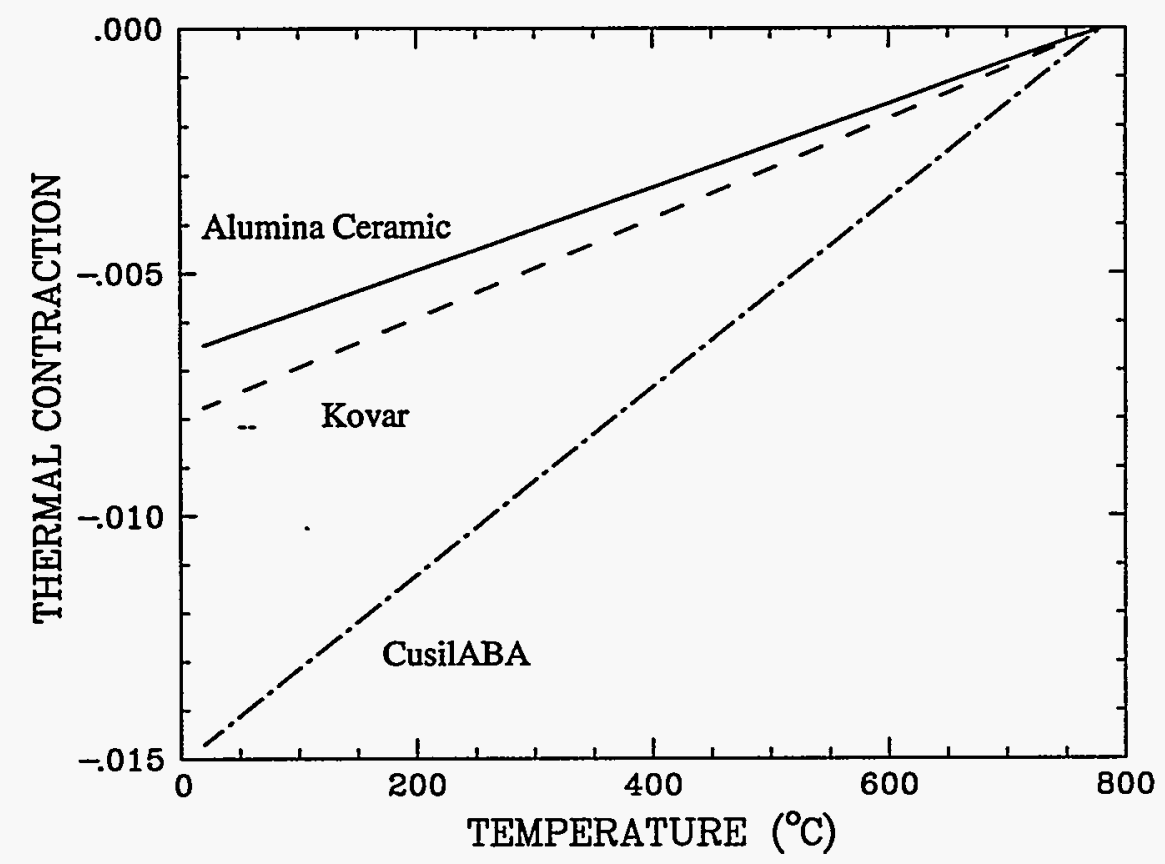

Figure 27. Linearized Thermal Expansion Properties of the Braze Joint Materials Used to Generate the Results Shown in Figures 28 through 30.

Results from these simulations indicated that when the new viscoplastic theory was used a maximum tensile stress of 79.5 MPa was generated in the alumina ceramic in Element 600 near the outer surface of the rod and near the braze joint (Figure 28). The stress distributions generated when the braze was modeled using the other constitutive theories was very similar to that shown in Figure 28. The maximum principal stress histories in Element 600 generated using the various constitutive theories for the braze layer are shown in Figure 29. These results indicate that the predicted maximum principal stress is largest when the power law creep theory is used for the braze. The stress histories generated using the power law creep theory and the new viscoplastic theory are very similar when the braze alloy is at an elevated temperature; however, at low temperatures the predictions generated by these theories diverge and the new viscoplastic theory tends to follow a slope that is similar to the slope generated with the vonMises plasticity theory. Results obtained using the new viscoplastic theory and material parameters from Tables 2, 3, and 4 are compared in Figure 30. The predictions generated using the new viscoplastic theory with the various material parameters are very similar. Thus, for this problem, the results are not very sensitive to the process used for material parameter selection or the assumptions made about whether the hardening / recovery is isotropic or kinematic.

The next series of simulations were performed using the actual thermal expansion properties of the braze joint materials (Figure 31). Note that the thermal expansion coefficient for both the Kovar and the alumina ceramic tends to increase with temperature. Our assumption in the previous analyses that the thermal expansion coefficient for the materials was constant over the temperature range of interest was not very accurate. 

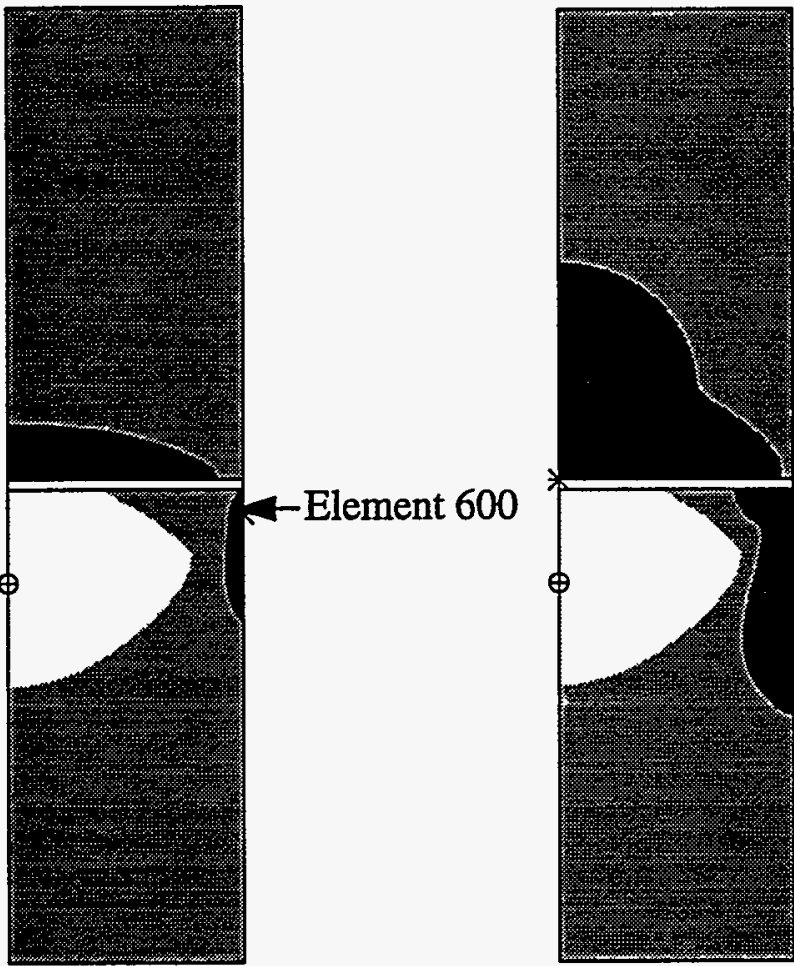

STRESS (MPa)

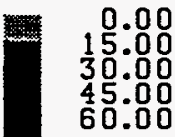

$\bigoplus=$ MINIMUM
$*=$ MAXIMUM

(a.) 1800 seconds $\left(400^{\circ} \mathrm{C}\right)$

(b.) 3600 seconds $\left(20^{\circ} \mathrm{C}\right)$

Figure 28. Maximum Principal Stress Distribution Generated in the Alumina Ceramic and Kovar Using Linearized Thermal Expansion of Joint Materials.

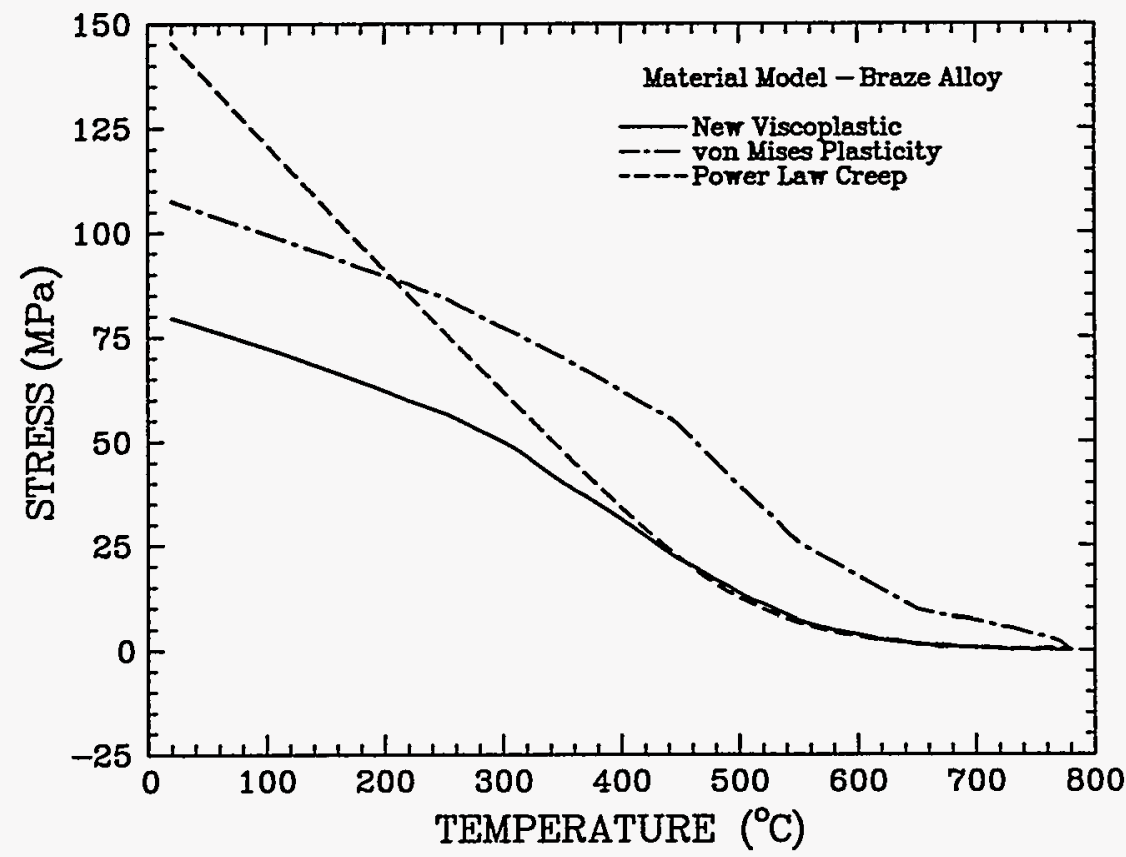

Figure 29. Effect of Braze Modeling Variations on the Maximum Principal Stress History for Element 600 - Linearized Thermal Expansion of Joint Materials. 


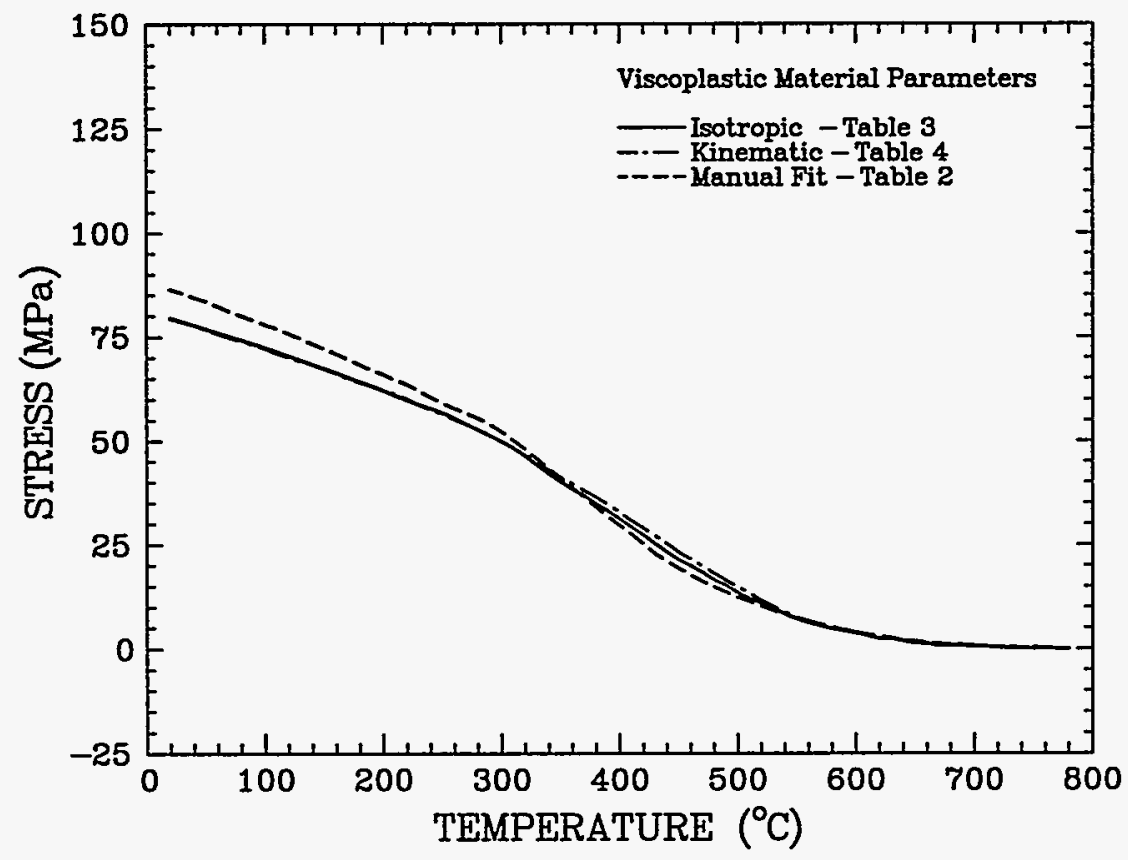

Figure 30. Effect of Braze Material Parameter Variations on the Maximum Principal Stress History for Element 600 - Linear Thermal Expansion of Joint Materials.

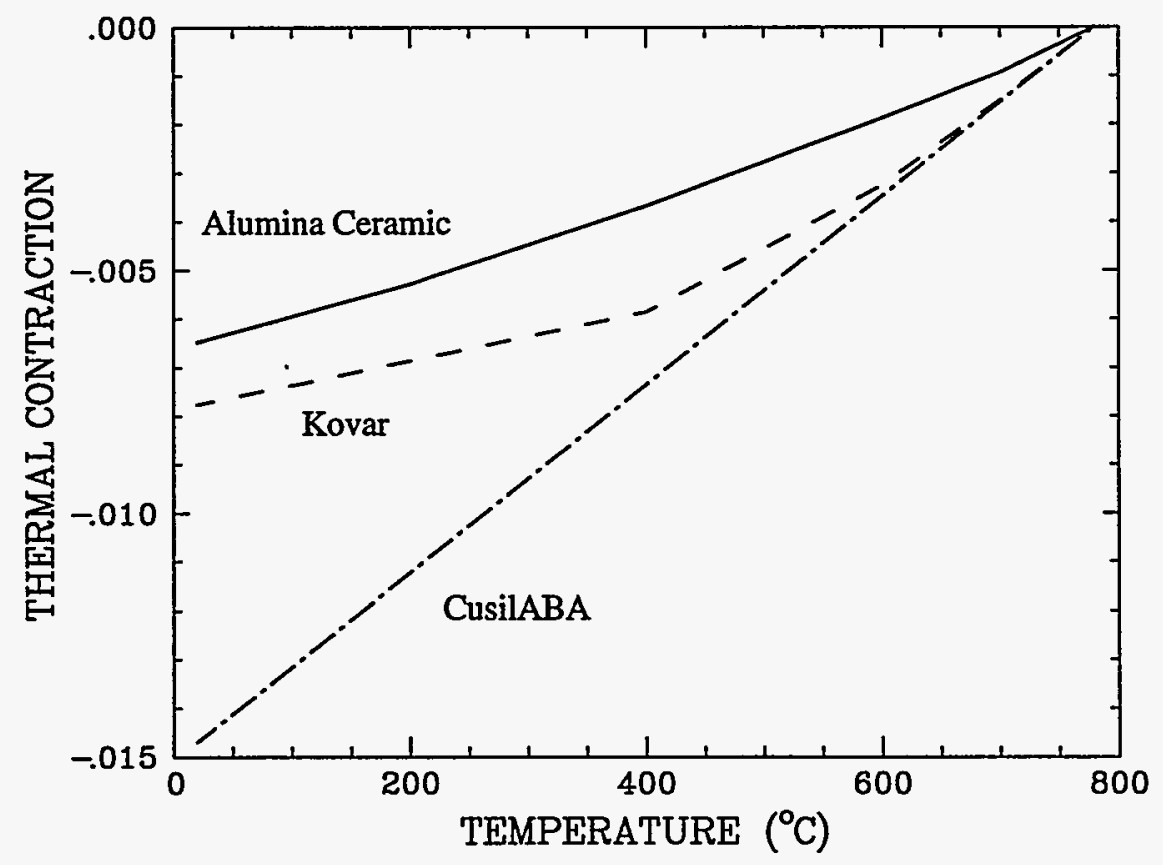

Figure 31. Actual Thermal Expansion Properties of the Braze Joint Materials. 
Results from the simulations with the new viscoplastic theory indicated that a maximum tensile stress of only $51.8 \mathrm{MPa}$ would be generated in the alumina ceramic during the brazing simulation at a time of 1800 seconds (Figure 32). At room temperature, the residual maximum tensile stress in the ceramic is only 16.2 MPa. The maximum principal stress history at Element 600 generated using the various constitutive theories for the braze layer are shown in Figure 33. These results indicate that the predicted maximum principal stress is largest when the vonMises plasticity theory is used for the braze. The stress histories generated using the power law creep theory and the new viscoplastic theories are very similar early in the simulation when the braze alloy is at a relatively high temperature; however at low temperature the predictions generated by these theories diverge. Results obtained using the new viscoplastic theory and material parameters from Tables 2, 3, and 4 are compared in Figure 34. The material parameter variations did have a small effect on the stress history prediction. A comparison of these analyses (Figures 33 and 34) with the previous analyses (Figures 29 and 30) indicates that the variations in the thermal contraction history had a very significant effect on the predictions and that accurate descriptions of the thermal contraction history are essential. In simulations of Kovar to alumina ceramic brazing with a eutectic Ag-Cu braze alloy, Stephens et al. (1992) also found that the predicted maximum tensile stress in the ceramic would be lower when the braze alloy was simulated using a viscoplastic theory in place of a von Mises plasticity theory.
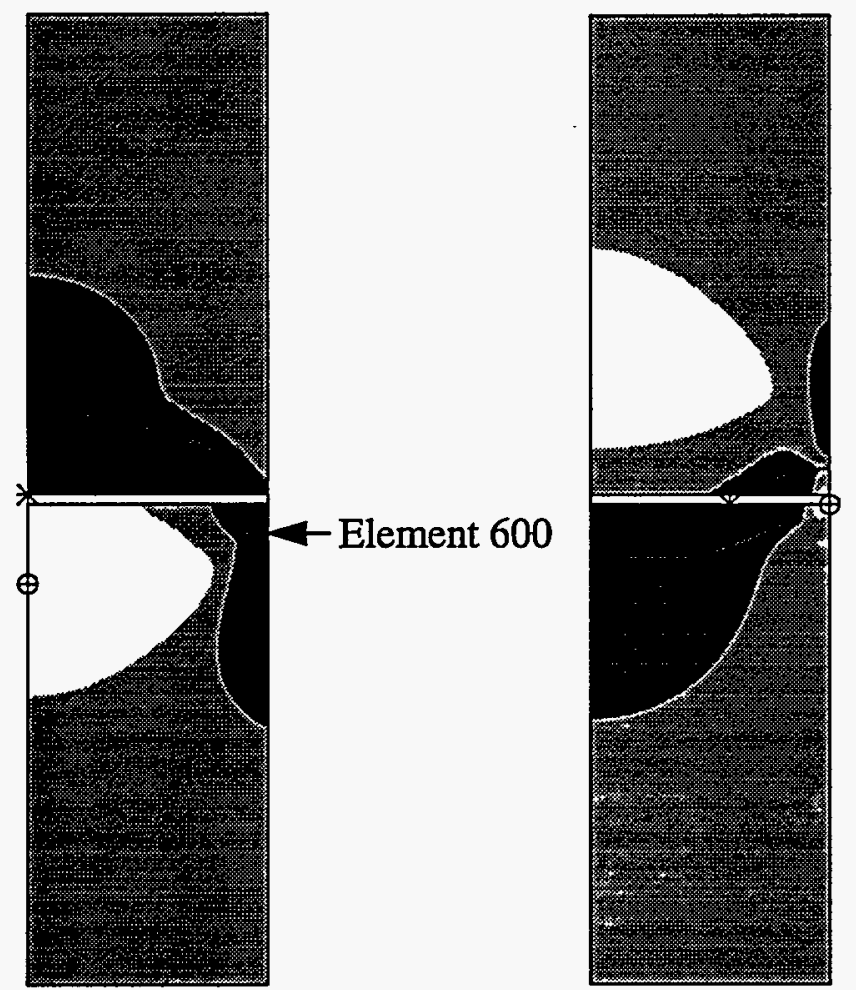

\section{STRESS (MPa)}

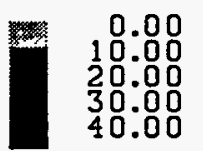

$\oplus=$ MINIMUM

* = MAXIMUM

(a.) 1800 seconds $\left(400^{\circ} \mathrm{C}\right)$

(b.) 3600 seconds $\left(20^{\circ} \mathrm{C}\right)$

Figure 32. Maximum Principal Stress Distribution Generated in the Alumina Ceramic and Kovar Using Actual Thermal Expansion of Joint Materials. 


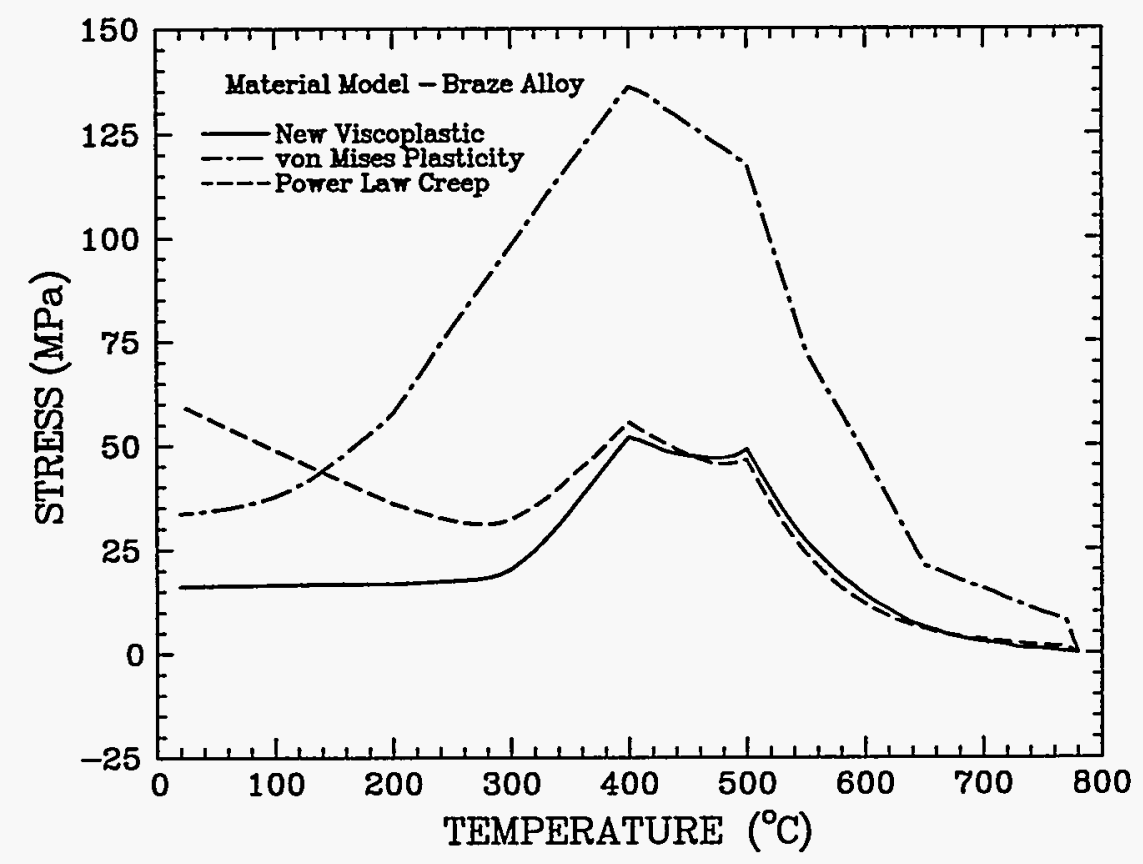

Figure 33. Effect of Braze Modeling Variations on the Maximum Principal Stress History for Element 600 - Actual Thermal Expansion of Joint Materials.

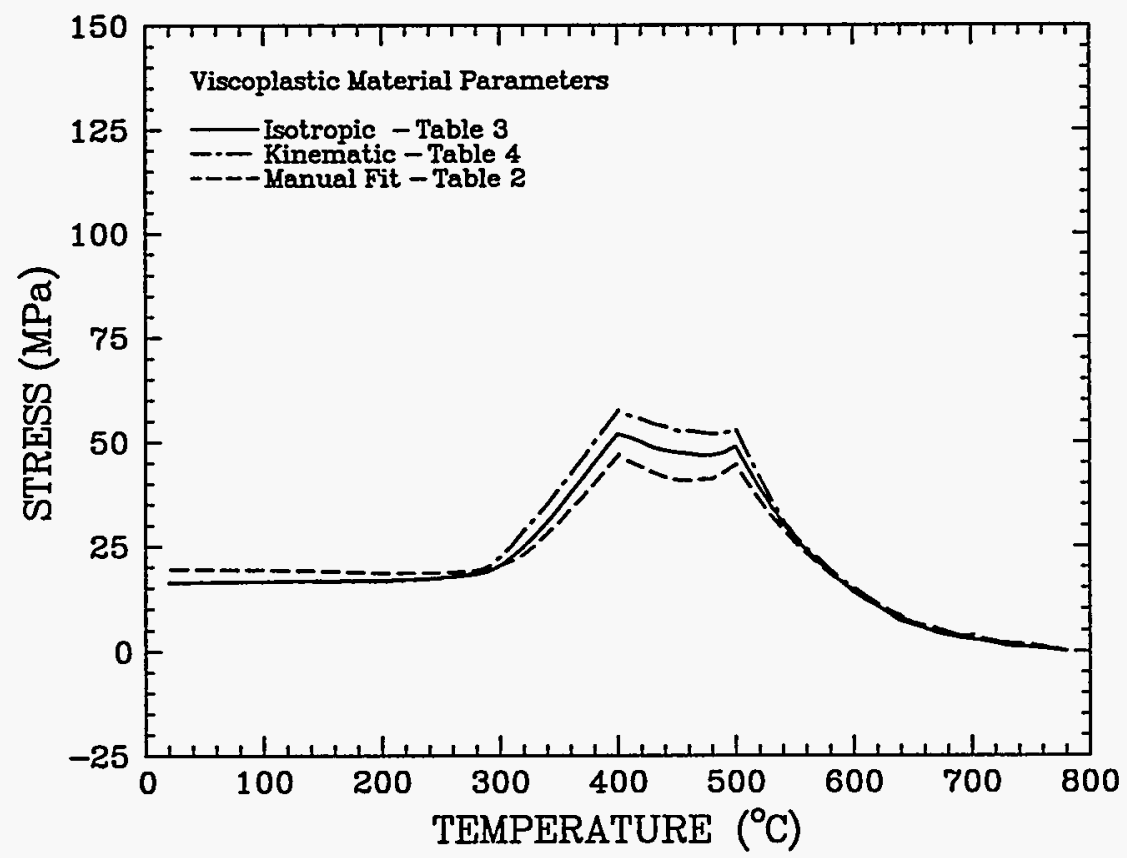

Figure 34. Effect of Braze Material Parameter Variations on the Maximum Principal Stress History for Element 600 - Actual Thermal Expansion of Joint Materials. 


\section{Summary and Future Work}

A new viscoplastic theory for braze alloys has been developed. Like previous viscoplastic theories, this new theory uses a hyperbolic sine function of effective stress in its kinetic equation for the inelastic strain rate. This new theory has an internal state variable to account for isotropic hardening and recovery and a second-order, internal state tensor to account for kinematic hardening and recovery. Unlike previous theories, the new theory uses evolution equations for the state variables which describe competing mechanisms of power law hardening and static recovery.

The new viscoplastic theory was implemented in the finite element codes: JAC2D (Biffle and Blanford, 1994), and JAS3D (Blanford, 1995). Uniaxial compression and creep compression tests on CusilABA were then simulated to compare the behavior predicted by the new theory with the experimental data and to ensure that the numerical implementation of the model was accurate. Finally, the metal-to-ceramic brazing of an alumina ceramic rod to a metal rod with CusilABA was simulated using existing constitutive theories and the new viscoplastic theory for the braze layer to investigate the effects of braze modeling variations on the results. As expected, the braze modeling variations were shown to have a significant effect on the residual stress predictions.

A logical next step for this research would be to perform a series of carefully instrumented metal-to-ceramic brazing experiments in which the deformations and strains generated during a brazing process are measured. Concurrently, numerical simulations of these experiments could be performed and stress and deformation history predictions could be generated. Results from these simulations could then be compared with the experimental results to evaluate the validity of our new viscoplastic theory for braze alloys.

Dissolution of material from a metal substrate can have a significant effect on the mechanical behavior of a braze alloy. The current model does not account for the effects of compositional gradients or solid solution strengthening, i.e., alloying due to base metal dissolution into the braze joint. These effects should be studied for both single and multi-phase braze alloys and included in future braze models.

The selection of appropriate material parameters for all internal state variable, viscoplastic theories is difficult because during even simple uniaxial compression and creep compression tests the state of the material is continuously changing. In this investigation, two approaches were used to obtain material parameters, a manual approach which used many simplifying assumptions and an automated approach which used a nonlinear least squares algorithm developed by Levenberg and Marquardt (More, 1978). Other researchers have used similar automated approaches (Senseny and Fossum, 1995; Lathrop, 1994). With the automated approach, material parameters were obtained by numerically simulating uniaxial compression and creep compression experiments and obtaining parameters which provide the best fit using nonlinear least squares. In the future, other optimization tools could be used to: (1) determine if parameters can be uniquely obtained from the existing test data, (2) help identify which additional tests are needed to obtain a unique set of material parameters, or (3) help identify constitutive theory variables which are dependent or are not important. 
Finally, the viscoplastic theories presented in this report, including the new theory, are difficult to integrate due to the mathematical stiffness of the associated differential equations. An evaluation of various numerical integration algorithms currently used for viscoplastic constitutive theories revealed that a forward Euler algorithm with adaptive time step size selection can be used to integrate these viscoplastic theories. Unfortunately, this simple algorithm may be computationally expensive in some regimes. Specifically, when the inelastic strain rates become large, such as for plasticity, the resulting critical time steps become very small. Alternate algorithms which deserve further investigation include: (1) asymptotic integration algorithms proposed by Freed, Yao and Walker (1992), and (2) a new integration algorithm proposed by Nemat- Nasser and Li (1994).

\section{References}

Bammann, D.J., "Modeling Temperature and Strain Rate Dependent Large Deformations of Metals," Appl. Mech. Rev., Vol. 43, No. 5, May 1990.

Biffle, J.H., and Blanford, M.L., "JAC2D - A Two-Dimensional Finite Element Computer Program for the Non-Linear Quasi-Static Response of Solids with the Conjugate Gradient Method," SAND93-1891, Sandia National Laboratories, May 1994.

Blanford, M.L., "Release 1.1 of JAS3D," internal memo, Sandia National Laboratories, July 1995.

Freed, A.D., Yao, M., and Walker, K.P., “Asymptotic Integration Algorithms for First-Order ODEs with Application to Viscoplasticity," NASA Technical Memo 105587, Lewis Research Center, Cleveland, OH, 1992.

Freed, A.D., and Walker, K.P., "Viscoplasticity with Creep and Plasticity Bounds," Intl. J. Plasticity, Vol. 9, No. 2, 1993.

Garofalo, F., Fundamentals of Creep and Creep-Rupture in Metals, The MacMillan Company, New York, 1965.

Gieske, J., "Dynamic Modulus Data for 67Ag-33Cu Alloy," internal memo, Sandia National Laboratories, November 1990.

Krieg, R. D., "Implementation of Creep Equations for a Metal Into a Finite Element Computer Program," Computer Methods for Nonlinear Solids and Structural Mechanics, AMD Vol. 54, A.S.M.E., 1983.

Lathrop, J.F., "BFIT - A Program to Analyze and Fit the Sandia Plasticity (BAMMANN) Model Parameters to Experimental Data," Internal Memo, Sandia National Laboratories, December 1994. 
Miller, A.K., Unified Constitutive Equations for Creep and Plasticity, Elsevier Applied Science, New York, NY, 1987.

Miller, A., "An Inelastic Constitutive Model for Monotonic, Cyclic, and Creep Deformation: Part 1 - Equations Development and Analytical Procedures," J. Engr. Mater. Tech., Vol. 98, April 1976.

More, J.J., "The Levenberg-Marquardt Algorithm: Implementation and Theory," Lecture Notes in Mathematics 630, Edited by G.A. Watson, Springer-Verlag, 1978.

Nemat-Nasser, S., and Li, Y.F., "An Algorithm for Large-Scale Computational Finite Deformation Plasticity," Mechanics of Materials, Vol. 18, 1994.

Senseny, P.E., and Fossum, A.F., "On Testing Requirements for Viscoplastic Constitutive Parameter Estimation," J. Engr. Mater. Tech., Vol. 117, April 1995.

Sherby, O.D., and Burke, P.M., "Mechanical Behavior of Crystalline Solids at Elevated Temperature," Progress in Materials Science, Vol. 13, 1968.

Stephens, J.J., Burchett, S.N., and Jones, W.B., "Stress Relaxation of Braze Joints," in Advances in Electronic Packaging, Edited by Chen, W.T., and Hiroyuki, A., EEP1-1, American Society of Mechanical Engineers, 1992.

Stephens, J.J., Hosking, F.M., and Burchett, S.N., "Creep Properties of the 62.2Ag-36.2Cu1.6Ti Active Metal Braze Alloy," Presented at the Annual TMS Meeting, Denver, CO, Febr. 1993.

Stone, C.M., and Morgan, H.S., "Vectorized Integration Scheme for Power-Law Secondary Creep Material Models," memo to Distribution, Sandia National Laboratories, Albuquerque, NM, July 1989.

Thomas, G.B., Jr., Calculus and Analytic Geometry, Addison-Wesley, Reading, MA, 1969.

Zienkiewicz, O.C., and Cormeau, I.C., "Visco-Plasticity - Plasticity and Creep in Elastic Solids - A Unified Numerical Solution Approach," Int. J. Numer. Meth. Engr., Vol. 8, 1974. 


\section{Appendix A - Material Parameter Names Used in JAC2D and JAS3D}

In JAC2D, the new viscoplastic material model is Material Type 8: Viscoplastic Braze

Table A1. Material Parameters Used in the JAC2D Implementation

\begin{tabular}{|l|l|}
\hline Material Parameter & \multicolumn{1}{|c|}{ Description } \\
\hline \hline Shear Modulus & Shear Modulus \\
\hline Bulk Modulus & Bulk Modulus \\
\hline Flow Rate & Natural Log of Parameter $\mathrm{f}$ in Equation 20 \\
\hline Sinh Exponent & Parameter $\mathrm{p}$ in Equation 20 \\
\hline Alpha & Parameter $\alpha$ in Equation 20 \\
\hline Isotropic Hardening & Parameter $\mathrm{A}_{1}$ in Equation 23 \\
\hline Isotropic Recovery & Parameter $\mathrm{A}_{2}$ in Equation 23 \\
\hline Kinematic Hardening & Parameter $\mathrm{A}_{4}$ in Equation 24 \\
\hline Kinematic Recovery & Parameter $\mathrm{A}_{5}$ in Equation 24 \\
\hline Flow Stress & Parameter $\mathrm{D}_{0}$ in Equation 23 \\
\hline Isotropic Exponent & Parameter $\mathrm{A}_{3}$ in Equation 23 \\
\hline Kinematic Exponent & Parameter $\mathrm{A}_{6}$ in Equation 24 \\
\hline
\end{tabular}

Table A2. State Variables Used in the JAC2D Implementation

\begin{tabular}{|l|l|}
\hline State Variable Name & \multicolumn{1}{|c|}{ Description } \\
\hline \hline EPX1 & State tensor component $-\mathrm{B}_{\mathrm{xx}}$ \\
\hline EPX2 & State tensor component $-\mathrm{B}_{\mathrm{yy}}$ \\
\hline EPX3 & State tensor component $-\mathrm{B}_{\mathrm{zz}}$ \\
\hline EPX4 & State tensor component $-\mathrm{B}_{\mathrm{xy}}$ \\
\hline EPX5 & State variable $-\mathrm{D}$ \\
\hline EPX6 & Accumulated Inelastic Strain \\
\hline EPX7 & Inelastic Strain Rate $-\gamma$ \\
\hline EPX8 & Subincrement Count - Inside Constitutive Model \\
\hline
\end{tabular}


In JAS3D, the new viscoplastic material model is Material Type 3: Viscoplastic

Table A3. Material Parameters Used in the JAS3D Implementation

\begin{tabular}{|c|c|}
\hline Material Parameter & Description \\
\hline Shear Modulus & Shear Modulus \\
\hline Bulk Modulus & Bulk Modulus \\
\hline Flow Rate & Natural Log of Parameter $f$ in Equation 20 \\
\hline Sinh Exponent & Parameter $\mathrm{p}$ in Equation 20 \\
\hline Alpha & Parameter $\alpha$ in Equation 20 \\
\hline Isotropic Hardening & Parameter $A_{1}$ in Equation 23 \\
\hline Isotropic Recovery & Parameter $\mathrm{A}_{2}$ in Equation 23 \\
\hline Kinematic Hardening & Parameter $\mathrm{A}_{4}$ in Equation 24 \\
\hline Kinematic Recovery & Parameter $\mathrm{A}_{5}$ in Equation 24 \\
\hline Flow Stress & Parameter $D_{0}$ in Equation 23 \\
\hline Isotropic Exponent & Parameter $\mathrm{A}_{3}$ in Equation 23 \\
\hline Kinematic Exponent & Parameter $\mathrm{A}_{6}$ in Equation 24 \\
\hline Shear Function & $\begin{array}{l}\text { Number of the Function which Prescribes the } \\
\text { Temperature Dependence of the Shear Modulus }\end{array}$ \\
\hline Bulk Function & ““ Bulk Modulus \\
\hline Rate Function & ““” Natural Log of Parameter $f$ in Equation 20 \\
\hline Exponent Function & “" Parameter $\mathrm{p}$ in Equation 20 \\
\hline Alpha Function & “" Parameter $\alpha$ in Equation 20 \\
\hline Ihard Function & “c Parameter $A_{1}$ in Equation 23 \\
\hline Irec Function & “" Parameter $\mathrm{A}_{2}$ in Equation 23 \\
\hline Khard Function & “c Parameter $\mathrm{A}_{4}$ in Equation 24 \\
\hline Krec Function & “s.Parameter $\mathrm{A}_{5}$ in Equation 24 \\
\hline
\end{tabular}


Table A4. State Variables Used in the JAS3D Implementation

\begin{tabular}{|l|l|}
\hline State Variable Name & \multicolumn{1}{|c|}{ Description } \\
\hline \hline SVBXX & State tensor component $-\mathrm{B}_{\mathrm{xx}}$ \\
\hline SVBYY & State tensor component $-\mathrm{B}_{\mathrm{yy}}$ \\
\hline SVBZZ & State tensor component $-\mathrm{B}_{\mathrm{zz}}$ \\
\hline SVBXY & State tensor component $-\mathrm{B}_{\mathrm{xy}}$ \\
\hline SVBYZ & State tensor component - $\mathrm{B}_{\mathrm{yz}}$ \\
\hline SVBZX & State tensor component $-\mathrm{B}_{\mathrm{zx}}$ \\
\hline SVC & State variable - D \\
\hline EQPS & Accumulated Inelastic Strain \\
\hline EQDOT & Inelastic Strain Rate \\
\hline COUNT & Subincrement Count - Inside Constitutive Model \\
\hline
\end{tabular}




\section{Appendix B - Development of Critical Time Step Size Criteria}

Integration of the Kinetic Equation for the Inelastic Strain Rate, Equation 20:

Zienkiewicz and Cormeau (1974) developed the following general stability criterion for the integration of a viscoplastic theory with the forward Euler algorithm

$$
\Delta t \leq \frac{2}{3 G f \Phi^{\prime}}
$$

where $\Delta t$ is the critical time step size, $G$ is the shear modulus, and $f$ and $\Phi$ are taken from the kinetic equation for the inelastic strain rate

$$
\gamma=\mathrm{f}(\theta) \Phi(\sigma)
$$

For the new viscoplastic theory for braze alloys

$$
\Phi=\sinh ^{\mathrm{p}}\left(\frac{\tau}{\alpha \mathrm{D}}\right)
$$

By taking the derivative of $\Phi$ with respect to $\tau$ and making appropriate substitutions, the following expression, Equation 26, is obtained for the critical time step size

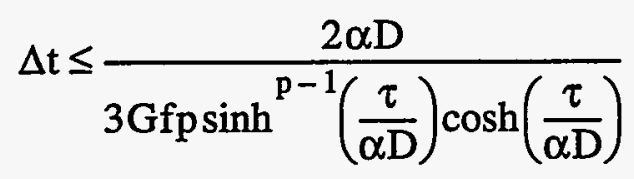

Integration of the Evolution Equations for the State Variables, Equations 23 and 24:

A Taylor series expansion of $\mathrm{D}(\mathrm{x})$ is given as follows (Thomas, 1969):

$$
D(t)=D(a)+D^{\prime}(a)(t-a)+\frac{D^{\prime \prime}(a)}{2 !}(t-a)^{2}+\cdots \cdot+\frac{D^{(n)}(a)}{n !}(t-a)^{n}+R_{n}
$$

where D'(a) is the first derivative of D with respect to the independent variable $t$, and $R_{n}$ is the remainder or a measure of the error and is given by

$$
R_{n}(t, a)=\int_{a}^{t} \frac{(t-x)^{n}}{n !} D^{(n+1)}(x) d x
$$


For forward Euler integration, $\mathbf{n}$ is equal to one and only the first term in the Taylor series expansion is used in the integration. Thus, the remainder or a measure of the error for this numerical integration is given by

$$
R_{1}(t, a)=\int_{a}^{t} \frac{(t-x)}{1} D^{\prime \prime}(x) d x
$$

If we assume that $D^{\prime \prime}(x)$ is approximately equal to $D$ ' (a), the value at the beginning of the time step, then the above equation generates the following estimate for the error

$$
\text { Error }=R_{1}(t, a) \approx \frac{\Delta t^{2}}{2} D^{\prime \prime}(a)
$$

Since we only have information at the beginning of the new step, an estimate for D' (a) is given by

$$
D^{\prime \prime}(a) \approx \frac{D^{\prime}(a)-D^{\prime}\left(a-\Delta t_{p}\right)}{\Delta t_{p}}
$$

where $\Delta t_{p}$ is the size of the previous time step and $D^{\prime}\left(a-\Delta t_{p}\right)$ is the first derivative of $D$ at the beginning of the previous time step. The following equation is then obtained from combining the above equations and setting the allowable error equal to $\delta D_{0}$, a small fraction of $D_{0}$

$$
\delta D_{0}=\frac{\Delta t^{2}}{2}\left(\frac{D^{\prime}(a)-D^{\prime}\left(a-\Delta t_{p}\right)}{\Delta t_{p}}\right)
$$

This equation can be rearranged to obtain the following criterion for the critical time step size

$$
\Delta t_{c}=\sqrt{\frac{2 \delta D_{0} \Delta t_{p}}{\left|D^{\prime}(a)-D^{\prime}\left(a-\Delta t_{p}\right)\right|}}
$$

The allowable step size is less than or equal to this critical step size as shown in Equation 27. A similar development was used to generate Equation 28. 


\section{Unlimited Release}

Ms. Ann Severin

Lucas-Milhaupt, Inc. .

5656 S. Pennsylvania Ave.

Cudahy, WI 53110

Dr. Toshi Oyama

WESGO, Inc.

477 Harbor Blvd.

Belmont, CA 94002

Prof. Raymond D. Krieg

Engineering Science and Mechanics

301 Perkins Hall

The University of Tennessee

Knoxville, TN 37996-2030

Prof. Roy Arrowood

Department of Metallurgical and Materials Engineering

University of Texas at El Paso

El Paso, TX 79968-0520

Prof. H.L. Schreyer

Department of Mechanical Engineering

University of New Mexico

Albuquerque, NM 87131 
Internal Distribution:

$\begin{array}{lll}\text { MS0841 } & 9100 & \text { P.J. Hommert } \\ \text { MS0835 } & 9102 & \text { R.D. Skocypec (Route to 9111) } \\ \text { MS0833 } & 9103 & \text { J.H. Biffle (Route to 9116) } \\ \text { MS0828 } & 9104 & \text { E.D. Gorham (Route to 9114, 9115) } \\ \text { MS0834 } & 9112 & \text { A.C. Ratzel (Route to 9113) } \\ \text { MS0443 } & 9117 & \text { H.S. Morgan (Route to Staff) } \\ \text { MS0437 } & 9118 & \text { E.P. Chen (Acting) (Route to Staff) } \\ \text { MS0443 } & 9117 & \text { S.N. Burchett } \\ \text { MS0443 } & 9117 & \text { A. Fossum } \\ \text { MS0443 } & 9117 & \text { S.W. Key } \\ \text { MS0443 } & 9117 & \text { M.K. Neilsen (20) } \\ \text { MS0443 } & 9117 & \text { C.M. Stone } \\ \text { MS0443 } & 9117 & \text { G.W. Wellman } \\ \text { MS0443 } & 9117 & \text { QA File } \\ \text { MS0340 } & 1832 & \text { W.R. Cieslak } \\ \text { MS0340 } & 1832 & \text { J.J. Stephens (3) } \\ \text { MS0340 } & 1832 & \text { T. Buchheit } \\ \text { MS9042 } & 8741 & \text { M.L. Chiesa } \\ \text { MS9401 } & 8743 & \text { M.L. Callabresi } \\ \text { MS9401 } & 8743 & \text { D.J. Bammann } \\ \text { MS9401 } & 8743 & \text { J. Lathrop } \\ \text { MS9018 } & 8523-2 & \text { Central Technical Files } \\ \text { MS0899 } & 4414 & \text { Technical Library (5) } \\ \text { MS0619 } & 12615 & \text { Print Media } \\ \text { MS0100 } & 7613-2 & \text { Document Processing For DOE/OSTI (2) } \\ & & \end{array}$




\section{DISCLAIMER}

This report was prepared as an account of work sponsored by an agency of the United States Government. Neither the United States Government nor any agency thereof, nor any of their employees, makes any warranty, express or implied, or assumes any legal liability or responsibility for the accuracy, completeness, or usefulness of any information, apparatus, product, or process disclosed, or represents that its use would not infringe privately owned rights. Reference herein to any specific commercial product, process, or service by trade name, trademark, manufacturer, or otherwise does not necessarily constitute or imply its endorsement, recommendation, or favoring by the United States Government or any agency thereof. The views and opinions of authors expressed herein do not necessarily state or reflect those of the United States Government or any agency thereof. 